\title{
TAp73 loss favors Smad-independent TGF- $\beta$ signaling that drives EMT in pancreatic ductal adenocarcinoma
}

\author{
AK Thakur ${ }^{1}$, J Nigri', S Lac ${ }^{1}$, J Leca ${ }^{1}$, C Bressy ${ }^{1}$, P Berthezene ${ }^{1}$, L Bartholin², P Chan ${ }^{3}$, E Calvo ${ }^{4}$, JL lovanna ${ }^{1}$, S Vasseur ${ }^{1}$, \\ F Guillaumond ${ }^{1}$ and $\mathrm{R}$ Tomasini ${ }^{* 1}$
}

Advances made in pancreatic cancer therapy have been far from sufficient and have allowed only a slight improvement in global survival of patients with pancreatic ductal adenocarcinoma (PDA). Recent progresses in chemotherapy have offered some hope for an otherwise gloomy outlook, however, only a limited number of patients are eligible because of important cytotoxicity. In this context, enhancing our knowledge on PDA initiation and evolution is crucial to highlight certain weaknesses on which to specifically target therapy. We found that loss of transcriptionally active p73 (TAp73), a p53 family member, impacted PDA development. In two relevant and specific engineered pancreatic cancer mouse models, we observed that TAp73 deficiency reduced survival and enhanced epithelial-to-mesenchymal transition (EMT). Through proteomic analysis of conditioned media from TAp73 wild-type (WT) and deficient pancreatic tumor cells, we identified a secreted protein, biglycan (BGN), which is necessary and sufficient to mediate this pro-EMT effect. Interestingly, BGN is modulated by and modulates the transforming growth factor- $\beta$ (TGF- $\beta$ ) pathway, a key regulator of the EMT process. We further examined this link and revealed that TAp73 impacts the TGF- $\beta$ pathway by direct regulation of BGN expression and Sma and Mad-related proteins (SMADs) expression/ activity. Absence of TAp73 leads to activation of TGF- $\beta$ signaling through a SMAD-independent pathway, favoring oncogenic TGF- $\beta$ effects and EMT. Altogether, our data highlight the implication of TAp73 in the aggressiveness of pancreatic carcinogenesis through modulation of the TGF- $\beta$ signaling. By suggesting TAp73 as a predictive marker for response to TGF- $\beta$ inhibitors, our study could improve the classification of PDA patients with a view to offering combined therapy involving TGF- $\beta$ inhibitors. Cell Death and Differentiation (2016) 23, 1358-1370; doi:10.1038/cdd.2016.18; published online 4 March 2016

Pancreatic ductal adenocarcinoma (PDA) is the most common form of pancreatic cancer with a very poor prognosis because of limited benefit allowed by current chemotherapy/radiotherapy approaches together with a late diagnosis. ${ }^{1}$ Moreover, according to incidence's prediction, ${ }^{2}$ PDA is now considered as a leading cause of cancer-related death worldwide. These marked epidemiological data highlight the crucial need to better understand pancreatic cancer development in order to improve the fate and quality of life of patients.

Recent advances of our knowledge of PDA biology and development highlighted the importance of the intra-tumor microenvironment, comprising up to $90 \%$ of the tumor mass. ${ }^{3}$ Indeed, the vast majority of these tumors are constituted by non-tumor cells such as cancer-associated fibroblasts (CAFs), immune cells (of varying composition depending on tumor state), nerve fibers or extracellular components. ${ }^{3,4}$ Over the last decade, a plethora of functions have been attributed to these components ${ }^{3}$ giving rise to numerous reviews highlighting the growing interest in targeting this non-tumor compartment or its consequent impact on tumor development, maintenance or evolution. ${ }^{5,6}$ Within this intra-tumor microenvironment compartment, non-cellular components such as extracellular matrix (ECM), to which both tumor cells and stroma contribute, are largely described and correlate with tumor aggressiveness and tumor cell abilities. ${ }^{7,8}$ ECM proteins, such as hyaluronic acid, were shown to act as a barrier to perfusion because of compression of pancreatic tumor blood vessels limiting the amount of drug reaching the tumor cells. ${ }^{9}$ Among these ECM proteins, the transforming growth factor $-\beta$ (TGF- $\beta$ ) acts in PDA as a potent tumor suppressor and tumor promoter in a contextdependent manner. ${ }^{10,11}$ In PDA, TGF- $\beta$ impacts are driven by Sma and Mad-related protein (SMAD)2/3/4 pathway activation/ inactivation as well as by SMAD-independent pathways, that is, phosphatidylinositol-3 kinase (PI3K)/protein kinase B (Akt) pathway, JNK/p38 non-Smad pathway or mitogen-activated protein kinase (MAPK) pathway. ${ }^{12,13}$ Overall, PDA studies support the notion that disabling TGF- $\beta /$ Smad 4 signaling pathway may be a critical event in pancreatic cancer progression, and open up a specific route toward the design of biomarkers as well as adjuvant therapies for this pathology. ${ }^{14}$

${ }^{1}$ CRCM, INSERM, U1068, Paoli-Calmettes Institute, Aix-Marseille University, UM 105; CNRS, UMR7258, Marseille, France; ${ }^{2} \mathrm{CRCL}$, INSERM, U1052; CNRS 5286, Centre Léon Bérard, Lyon, France; ${ }^{3}$ PISSARO Proteomic facility, (IRIB), U-Rouen, Mont Saint- Aignan, France and ${ }^{4}$ Molecular Endocrinology and Oncology Research Center, CHUL Research Center, Quebec, Canada

${ }^{*}$ Corresponding author: R Tomasini, CRCM, Cellular Stress, INSERM U1068, Paoli-Calmettes Institute, Aix-Marseille University, UM 105, CNRS, UMR7258, F-13009, Marseille F-13009, France. Tel: +33 4918288 15; Fax: +33 4918260 83; E-mail: richard.tomasini@inserm.fr

Abbreviations: TGF- $\beta$, transforming growth factor- $\beta$; EMT, epithelial-to-mesenchymal transition; PDA, pancreatic ductal adenocarcinoma; TAp73, transcriptionally active p73; BGN, biglycan; SMADs, Sma and Mad-related proteins; CAFs, cancer-associated fibroblasts; ECM, extracellular matrix; Akt, protein kinase B; Pl3K, phosphatidylinositol-3 kinase; MAPK, mitogen-activated protein kinase; KRAS, Kirsten rat sarcoma protein; CDKN2A, cyclin-dependent kinase inhibitor 2A; CNVs, copy number variations; Pdx1, pancreatic and duodenal homeobo X gene 1; $\alpha \mathrm{SMA}, \alpha$ smooth muscle actin; CM, conditioned media

Received 12.6.15; revised 01.2.16; accepted 02.2.16; Edited by RA Knight; published online 04.3.16 
To date, although studies involving stromal components are revealing some potential therapeutic targets, genetic and epigenetic studies have identified mutated/altered pathways in the tumor cells engulfed within the tumor mass, consisting mainly of KRAS, CDKN2A, SMAD4/DPC4, Hedgehog and TP53 mutations, among others. ${ }^{15,16}$ Interestingly, considering their involvement in events linked with control of cellular proliferation, the role of the first four pathways is fairly well described, however, the impact of p53 mutations remains unclear. The epidemiologic implication of TP53 mutations in PDA is even more interesting considering the intricate functional network formed by p53 and its family members. Indeed, 20 years ago, two genes were discovered and classified as being TP53 related because of their structural and functional homologies. Today, the roles of these genes, named TP63 and TP73, are better understood and they have been implicated in various processes. Although both p63 and p73 have been associated with the control of the cell cycle, cell death and maternal reproduction ${ }^{17,18}$ among other functions, p73 has also been implicated in cancer. We previously showed that loss of the full p73 isoform TAp73 (transcriptionally active p73), containing the transactivation domain similar to p53, induced spontaneous tumor development because of enhanced genomic instability. ${ }^{19,20}$ Interestingly, such genomic instability with loss of the spindle assembly checkpoint, was also reported in PDA where it was found associated with p73 inhibition. ${ }^{21}$ Moreover, although mutations in TP73 are less frequent in human cancers than those of TP53, genetic aberrations of TP73 were reported in pancreatic cancer and correlated with patient outcome. ${ }^{22}$ Based on the known impact of p53 in human and mouse models of PDA, ${ }^{23}$ and on the potential role of TAp73 in inflammation and cancer crosstalk, ${ }^{24}$ we wished to deepen our knowledge of TAp73 roles and functions in PDA.

To identify molecular targets of TAp73 with consequent roles in PDA development and/or associated metastasis, we generated mouse models of PDA with or without TAp73 deficiency and developed cell lines from the arising tumors. Here, we provide evidence that genetic depletion of TAp73 in pancreatic cancer cells leads to an enhanced malignant phenotype with acquisition of migration/invasion abilities. These modified processes are associated with decreased expression of the TGF- $\beta$ inhibitor biglycan (BGN) and SMAD4 activity acting as modulator and effector. Our data enhance our knowledge on the role of SMAD/TGF- $\beta$ pathway in pancreatic cancer and revive the interest in their exploitation as adjuvant therapies or prognostic markers.

\section{Results}

TAp73 loss is associated with PDA progression. Fourteen patients with PDA underwent fine needle aspiration of the pancreas. We used hapmap to analyze the biopsies obtained for copy number variations (CNVs) as compared with unpaired universal baseline (blood samples). Interestingly, in our cohort, $86 \%$ of PDA patients (12/14) highlighted genomic alterations (deletions) of the TP73 locus in five different segments from 2 to 29 thousands base pairs (bps), with similar significant $P$-value of $5.96 \mathrm{e}^{-17}$ (Supplementary
Figure S1). Those data are in range with information from available public data set reporting modulation of TP73 expression in pancreatic cancer (\#GDS4102 and \#GDS4103). Deletions of classical PDA-associated genes (Ink4a/Arf locus 86\%, Kras 75\% and Smad4 43\%) also observed in our study confirmed its robustness. This finding suggests a possible implication of TP73 locus deletion in PDA initiation/progression and validates the interest of this study.

To analyze the impact of TAp73 loss in PDA, we crossed a genetically engineered mouse model ( $P d x 1-C r e / L S L$ -

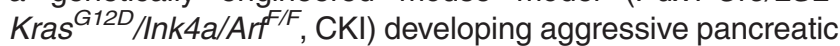
cancer with epithelial-to-mesenchymal transition (EMT) phenotype $^{25}$ with a previously generated TAp73-deficient mouse (TA; Supplementary Figure S2a). ${ }^{19}$ In our cohort, the CKI mice yielded lethal pancreatic tumors by a median of 66 days old, which is consistent with a previous study (Figure 1a; $n=19) .{ }^{26}$ However, the associated TAp73 nullizygosity (CKITA mice) significantly decreased median survival to a median of 52 days of age (Figure $1 \mathrm{a} ; n=8, P<0.0001$ ). Interestingly, although both models developed PDAs, histopathological analysis of PDA from CKITA mice revealed an increase of stromal compartment compared with that in PDA from CKI mice (Figure 1b); this was confirmed by an enhanced deposition of ECM (Figures 1c and d) and expression of the CAF marker, $a$-smooth muscle actin (aSMA; Figures 1e and f). Interestingly, PDA developed in this homozygous-null TAp73 model showed similar histology as well as close progression kinetic to that observed in TP53 ${ }^{-1-}$ background, with a median lethality of 50 days. ${ }^{27}$ These data suggest that while both act in limiting PDA development, p53 and TAp73 showed no compensatory activity in this physiological context.

These data were confirmed using the CKIH mice ( $P d x 1-C r e /$ LSL-Kras ${ }^{G 12 D} / I n k 4 a / A r f^{F /+}$ ) (Supplementary Figure S2b). Similarly to the original study, ${ }^{27} \mathrm{CKIH}$ mice developed PDA with a longer latency of 227 days compared with the 66 days of CKI mice (Supplementary Figure S2c; $n=19$ and 9, respectively, $P<0.0001)$, and combination with TA mice shortened the latency of CKIH mice from 227 to 169 days for CKIHTA (Figure 1g; $n=9$ and 8 , respectively, $P=0.035$ ). Altogether, with similar clinical representation across the various PDA models, these data reveal that, as reported for the PDA mouse model carrying a loss of TP53, TAp73 functions as a potent barrier to PDA progression.

Increase of EMT markers in PDA harboring TAp73 deficiency. Survival and histological data suggest that the PDA that arose in CKITA mice exhibited features of enhanced aggressiveness. Recent studies in PDA models reported enhanced aggressiveness as associated with acquisition of an EMT phenotype. ${ }^{25,28}$ At the molecular level, EMT is characterized by downregulation of E-cadherin expression and acquisition of mesenchymal markers such as vimentin and aSMA but also $\mathrm{N}$-cadherin, ${ }^{29}$ which is positively correlated with EMT transition and negatively correlated with survival of PDA patients. ${ }^{30}$ By analyzing PDA arising from CKI or CKITA mice, we found an increase in both $\mathrm{N}$-cadherin (Figures $2 a$ and $b$ ) and vimentin (Figures $2 c$ and $d$ ) staining in PDA from CKITA mice. These data were confirmed by measurements of $\mathrm{N}$-cadherin and vimentin in protein extracts 


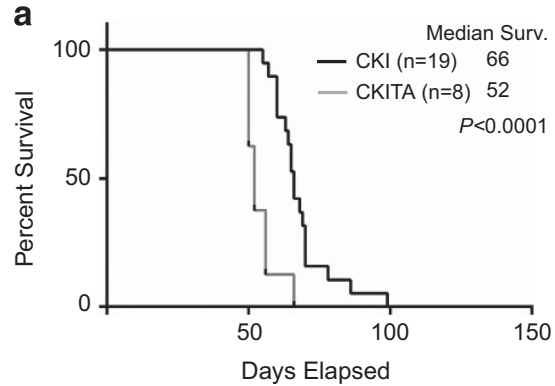

C

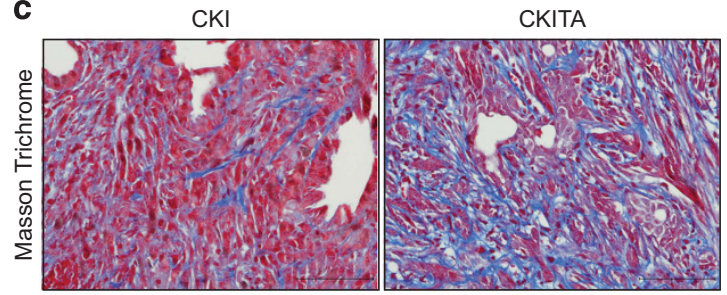

e
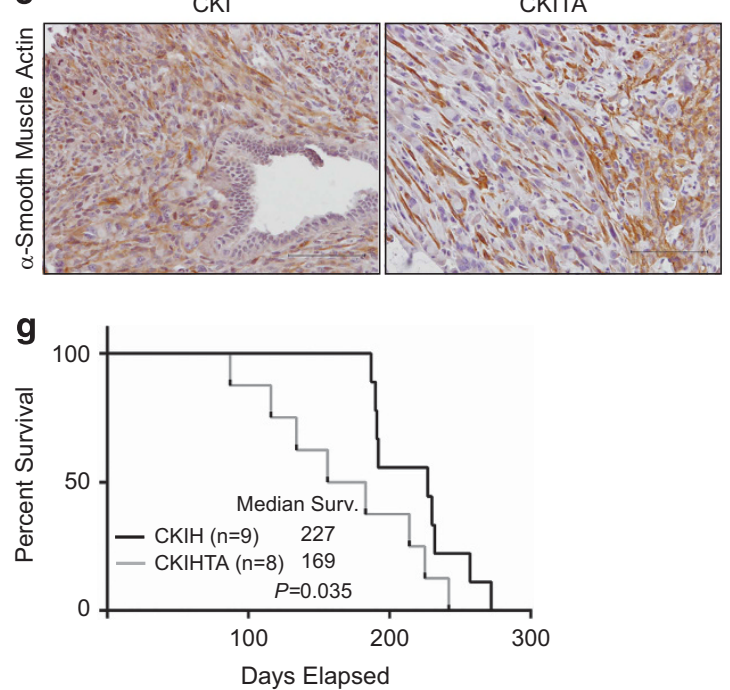

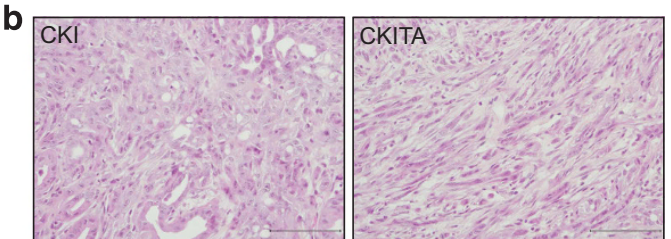

d

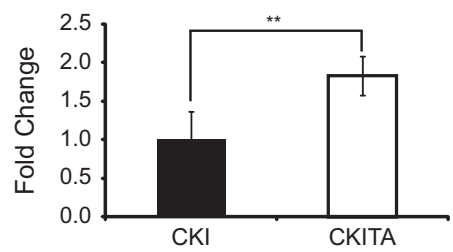

$\mathbf{f}$

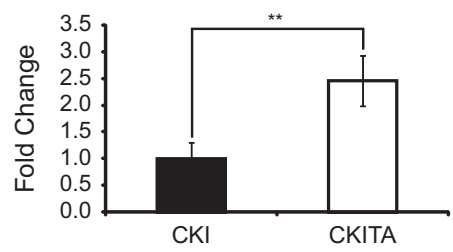

Figure 1 TAp73 is a tumor suppressor in Kras-driven PDA mouse models. (a) Median survival curves of CKI and CKITA mice (Gehan-Breslow-Wilcoxon; $P<0.0001, n=19$ and 8 for CKI and CKITA, respectively). (b) Representative H\&E histology from two independent CKI and CKITA pancreas. Scale bar represents $100 \mu \mathrm{m}$. (c) Representative Masson Trichrome staining in PDA sections from CKI and CKITA mice, as quantified in $\mathbf{d}$ using unpaired Student's $t$-test ${ }^{* *} P<0.01$ ). Scale bars represent $100 \mu \mathrm{m}$. (e) Representative $\alpha$ SMA staining in PDA sections from CKI and CKITA mice, as quantified in $\mathbf{f}$ using unpaired Student's $t$-test $\left({ }^{* *} P<0.01\right)$. Scale bars represent $100 \mu \mathrm{m}$. (g) Median survival curves of CKIH and CKIHTA mice (Gehan-Breslow-Wilcoxon; $P=0.035, n=9$ and 8 for CKIH and CKIHTA, respectively). Error bars represent S.D.

from CKI and CKITA PDAs (Figure 2e). Concomitantly, we observed significantly lower levels of expression of E-cadherin in PDA from CKITA mice versus in PDA from CKI mice (Figures $2 e$ and g). We also observed a significant increase in the level of expression of Snail, an EMT-related transcription factor, ${ }^{31}$ in TAp73-deficient PDA (Figures $2 \mathrm{~h}$ and i). Altogether, these data reveal that EMT markers are increased in TAp73-deficient PDA suggesting that TAp73, like p53, ${ }^{32}$ limits the EMT process and PDA aggressiveness.

TAp73 loss potentiates EMT-related cellular abilities. To definitively assess TAp73 involvement in EMT regulation, we studied EMT markers and EMT-related phenotypes of isolated murine PDA cell lines from CKI $\left(4 \mathrm{~A} ; \mathrm{TAp} \mathrm{3}^{+/+}\right)$and
CKITA (W1; TAp73---) PDA. By phase contrast microscopy, the $4 \mathrm{~A}$ cells $\left(T A p 73^{+/+}\right)$had a pebble-like shape with tight cell-cell adhesions, whereas the W1 cells $\left(\operatorname{TAp}^{-1-}\right)$ were more elongated in shape, and displayed fibroblast-like appearance (Supplementary Figure S3a). We also noted a significant decrease in the epithelial marker E-cadherin together with an increase in mesenchymal markers ( $\mathrm{N}$-cadherin and vimentin) in the $\mathrm{W} 1$ cells versus the $4 \mathrm{~A}$ cells (Figure $3 \mathrm{a}$ ), suggesting that $\mathrm{W} 1$ cells harbor an enhanced EMT phenotype. Analysis of their proliferative rate revealed that TAp73 loss induced a decrease in proliferation (Figure $3 b$ ) associated with a decreased $\mathrm{S}$ phase percentage (Supplementary Figure S3b), a known characteristic of EMT cells, ${ }^{29}$ consistent with the decreased Ki67 staining observed 
a

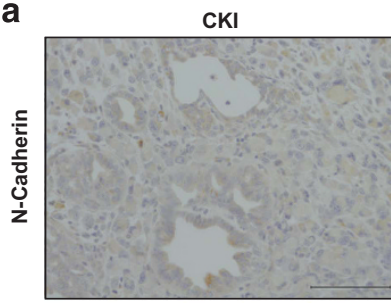

C

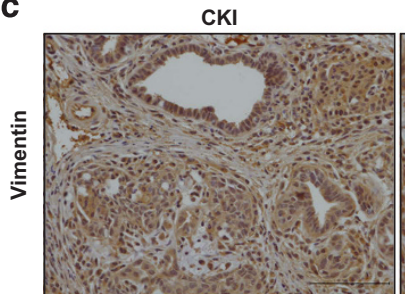

CKITA

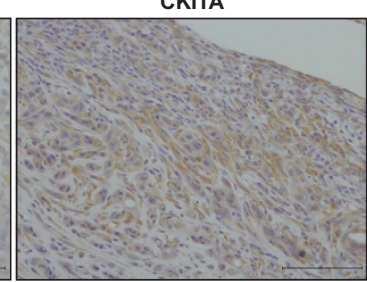

CKITA

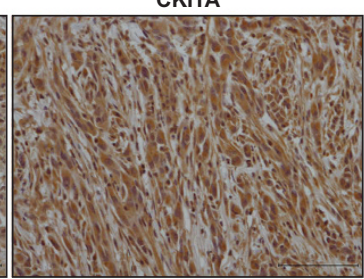

b

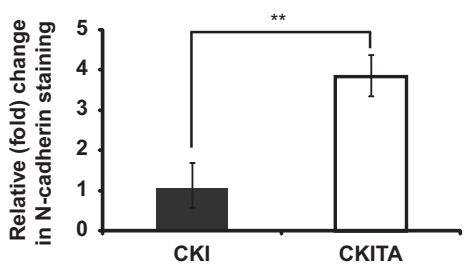

d

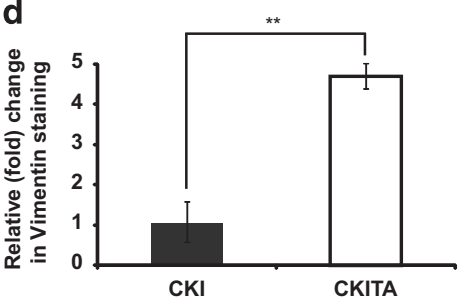

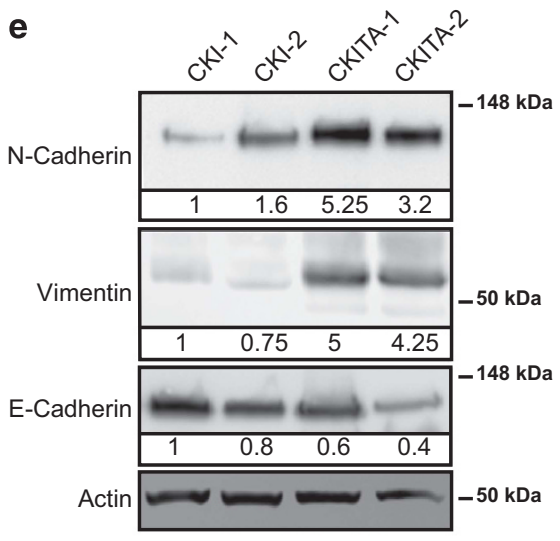

f
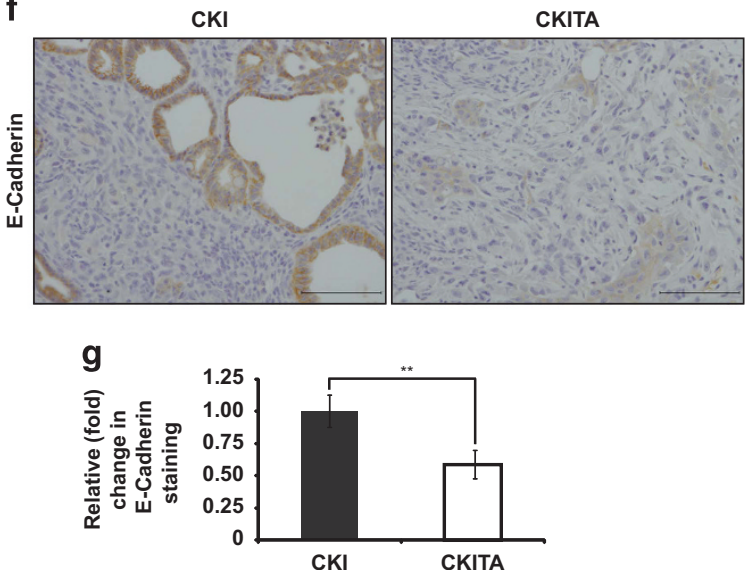

h
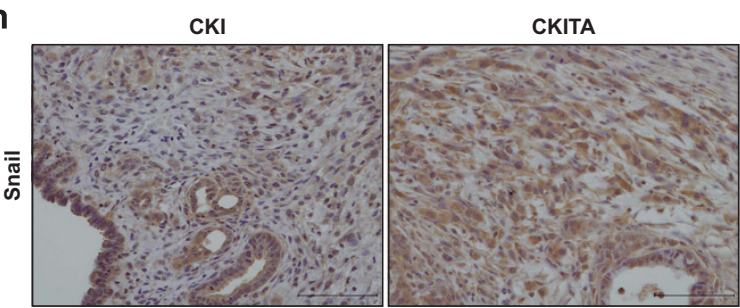

i

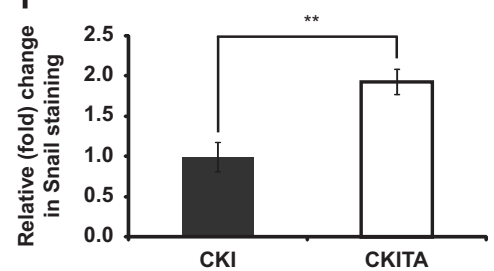

Figure 2 Epithelial tumor cells in TAp73-/- PDA displaying EMT markers. (a) Representative N-cadherin staining in PDA sections from CKI and CKITA mice, as quantified in b using unpaired Student's $t$-test $\left({ }^{* \star} P<0.01\right)$. Scale bars represent $100 \mu \mathrm{m}$. (c) Representative vimentin staining in PDA sections from CKI and CKITA mice, as quantified in d using unpaired Student's $t$-test $\left({ }^{* *} P<0.01\right)$. Scale bars represent $100 \mu \mathrm{m}$. (e) Representative immunoblots and quantification of $\mathrm{N}$-cadherin, vimentin and $\mathrm{E}$-cadherin expression in PDA extracts from CKI and CKITA mice. ( $f$ ) Representative E-cadherin staining in PDA sections from CKI and CKITA mice, as quantified in $\mathbf{g}$ using unpaired Student's $t$-test $\left({ }^{* *} P<0.01\right)$. Scale bars represent $100 \mu \mathrm{m}$. (h) Representative Snail staining in PDA sections from CKI and CKITA mice, as quantified in i using unpaired Student's $t$-test $\left({ }^{* \star} P<0.01\right)$. Scale bars represent $100 \mu \mathrm{m}$. Error bars represent S.D.

in PDA from CKITA mice (Figures 3c and d). As expected for EMT cells, we also observed that W1 cells $\left(\operatorname{TAp}^{-1-}\right)$, as well as Panc1 Human PDA tumor cell transfected with a TAp73 siRNA (siTAp73), showed enhanced migratory (Figure 3e) and invasive (Figure $3 f$ ) abilities, compared with $4 \mathrm{~A}$ cells $\left(\mathrm{TAp}^{+/+}\right)$and to Panc1 human PDA tumor cell transfected with a control siRNA (siCtr), respectively. Moreover, as the presence of EMT in PDA was shown to be a predictor of gemcitabine resistance, ${ }^{33}$ we measured the cell death rate following gemcitabine treatment and observed a reduced sensitivity to this treatment in W1 cells $\left(\operatorname{TAp}_{73^{-1}}\right)$ as

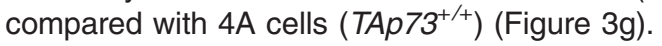

Finally, in vivo experiments involving intra-pancreatic injection of W1 and 4A cell lines confirmed this EMT-prone phenotype. Indeed, although we observed no difference with regards to the size of primary tumors (Supplementary Figure S3c), the number of liver metastases observed following injection of the TAp73-deficient cell line W1 was 


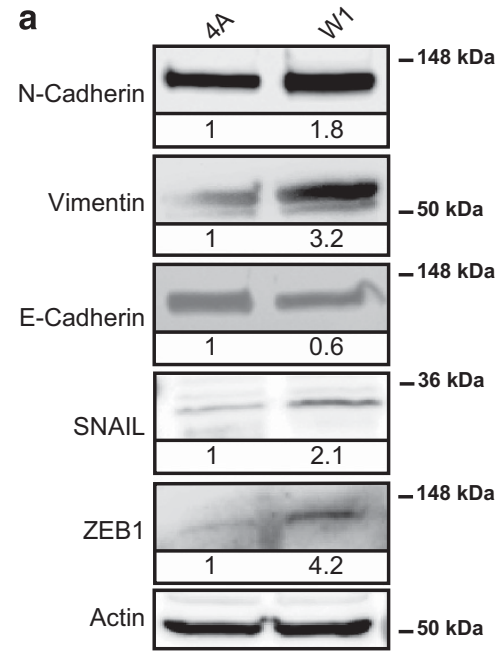

C

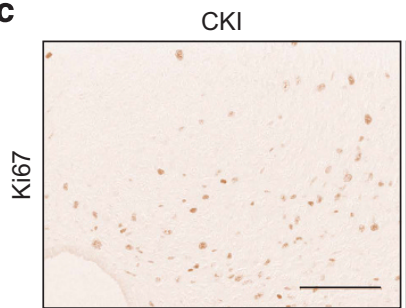

e

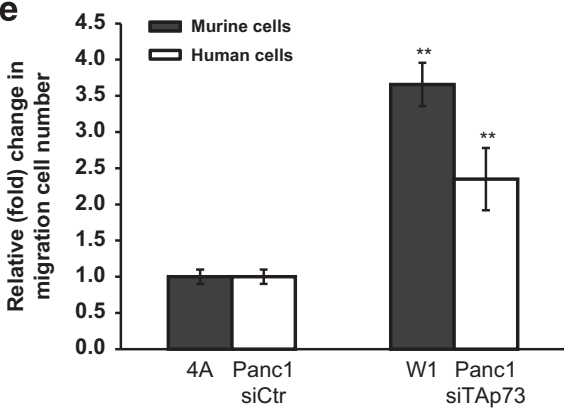

g

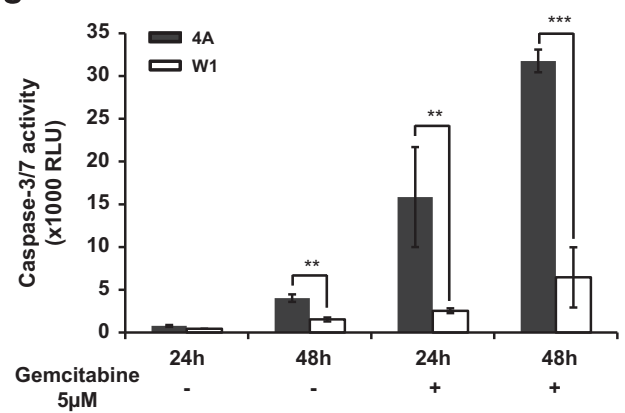

CKITA
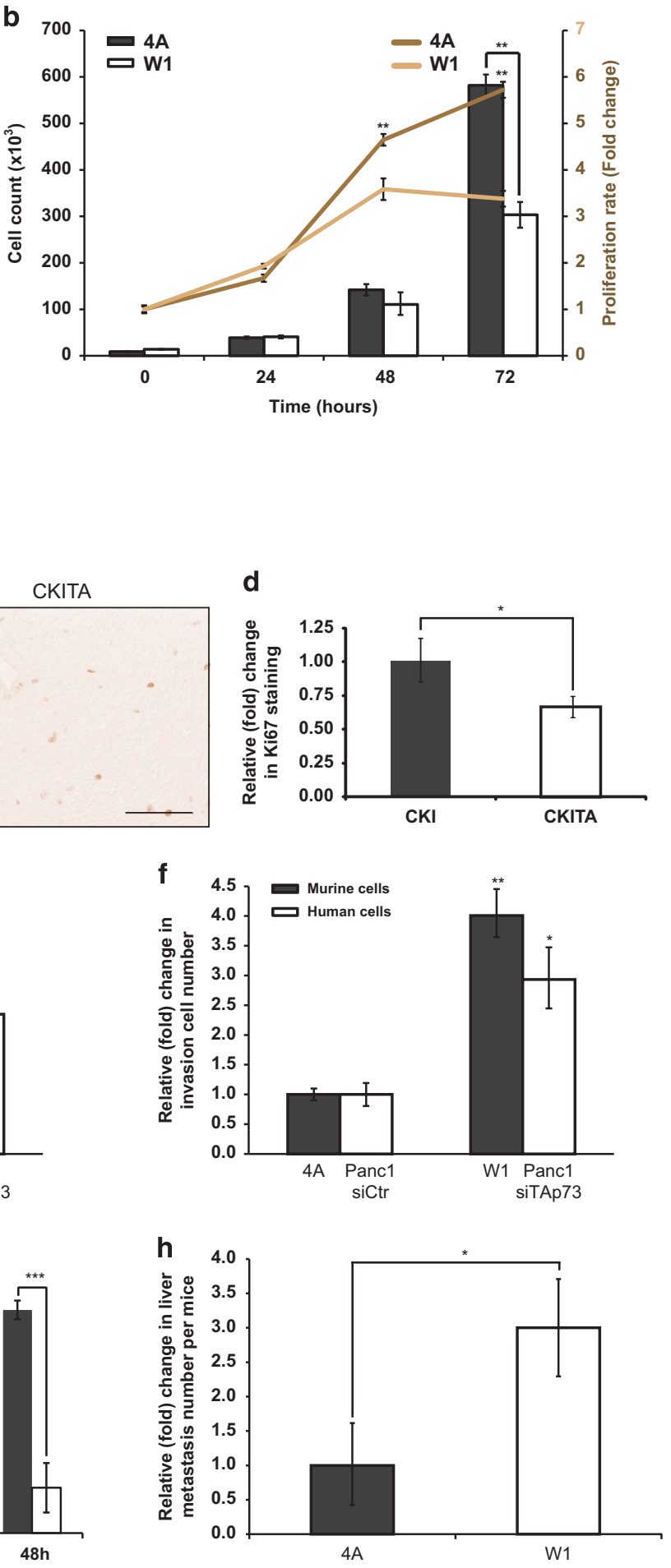

Figure 3 TAp73 loss enhances EMT-related cellular abilities. (a) Representative immunoblots and quantification of N-cadherin, vimentin and E-cadherin expression in 4A

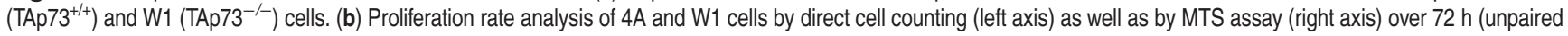
Student's $t$-test; $\left.{ }^{* *} P<0.01\right)$. (c) Representative Ki67 staining in PDA sections from CKI and CKITA mice, as quantified in d using unpaired Student's $t$-test $\left({ }^{*} P<0.05\right)$. Scale bars represent $100 \mu \mathrm{m}$. (e) Relative (fold) increase in the number of migratory W1 compared with $4 \mathrm{~A}$ cells (unpaired Student's $t$-test; ${ }^{* *} P<0.01$ ). (f) Relative (fold) increase in the number of invasive W1 compared with 4A cells (unpaired Student's $t$-test; ${ }^{* *} P<0.01$ ). (g) Cell death induction was measured by caspase-3/7 activity in $4 \mathrm{~A}$ and W1 cells treated with $5 \mu \mathrm{M}$ gemcitabine for 24 or $48 \mathrm{~h}$ (unpaired Student's t-test; ${ }^{* \star} P<0.01 ;{ }^{* \star} P<0.001$ ). Error bars represent S.D. (h) Relative (fold) increase in the number of liver metastases per mouse, 4 weeks after intra-pancreatic injection of $4 \mathrm{~A}$ or W1 cells (unpaired Student's t-test; ${ }^{*} P<0.05, n=8$ and 9 for $4 \mathrm{~A}$ and W1 injected mice, respectively). Error bars represent S.E.M. 
a

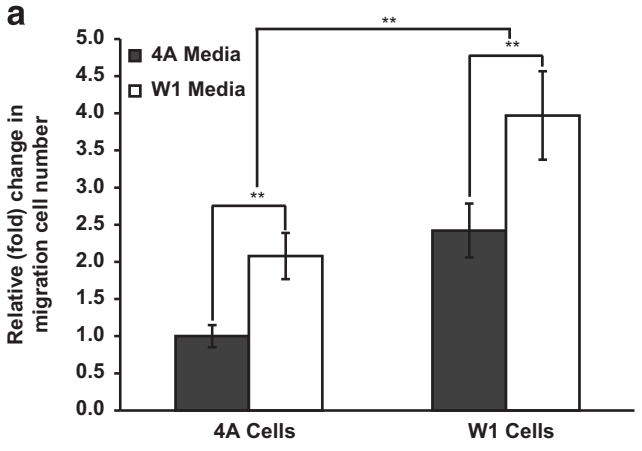

b

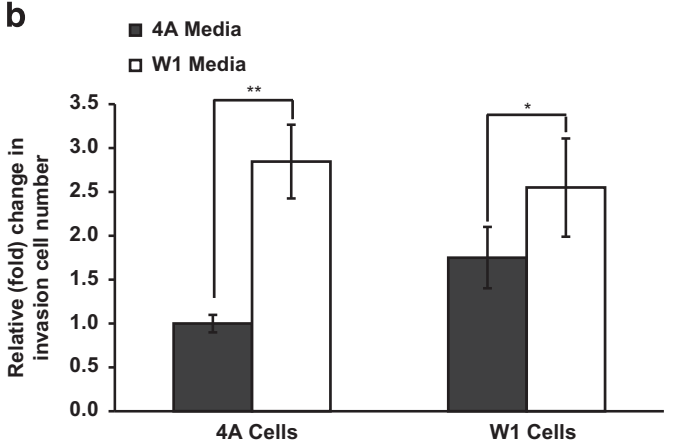

C

\begin{tabular}{|l|c|c|c|c|}
\hline Protein & Gene Name & Peptides & Coverage & Mean Expression Ratio \\
\hline Biglycan & Bgn & 3 & 0.0596 & 0.318 \\
\hline Fibulin-2 & Fbln2 & 7 & 0.0377 & 0.386 \\
\hline Mesothelin & Msln & 6 & 0.104 & 0.401 \\
\hline Metalloproteinase inhibitor 2 & Timp2 & 3 & 0.114 & 0.413 \\
\hline Clusterin & Clu & 12 & 0.261 & 0.441 \\
\hline Prolactin-2C2 & Prl2c2 & 3 & 0.103 & 2.1 \\
\hline Cathepsin D & Ctsd & 7 & 0.134 & 0.559 \\
\hline Galectin-3-binding protein & Lgals3bp & 5 & 0.101 & 0.584 \\
\hline Ubiquitin & Rps27a & 5 & 0.658 & 1.68 \\
\hline Vimentin & Vim & 5 & 0.152 & 1.67 \\
\hline
\end{tabular}

d

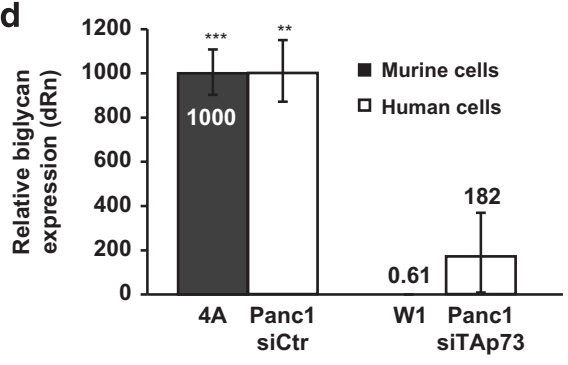

e

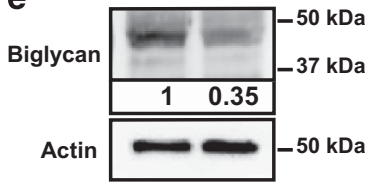

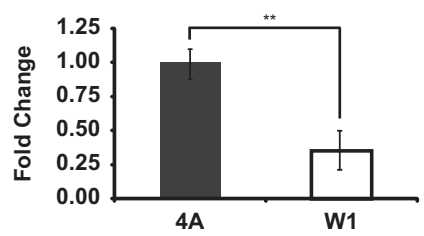

f

CKI

CKITA
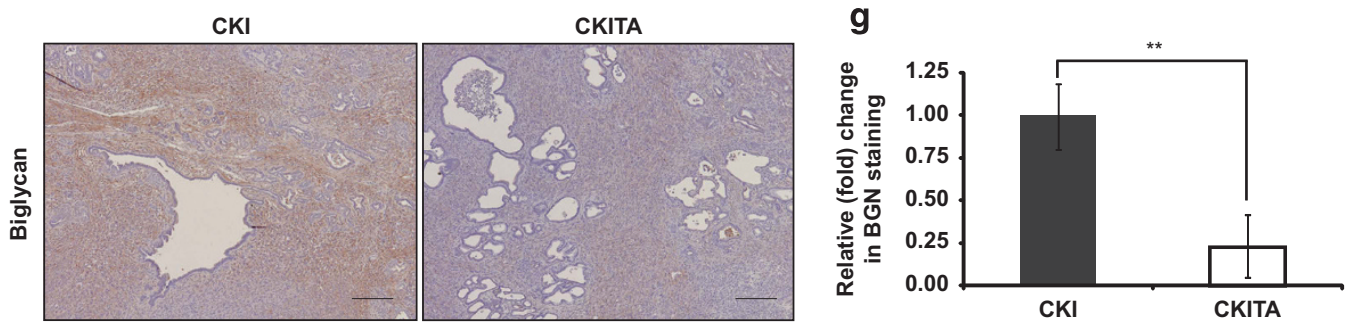

Figure 4 Secretome modulation in absence of TAp73 impacts EMT-related abilities. (a) Relative (fold) change in migratory 4A and W1 cells when cultivated with W1 media or $4 \mathrm{~A}$ media respectively (unpaired Student's $t$-test; ${ }^{* *} P<0.01$ ). (b) Relative (fold) change in invasive $4 \mathrm{~A}$ and W1 cells when cultivated with W1 or 4A CM (unpaired Student's $t$-test; $\left.{ }^{\star} P<0.05 ;{ }^{* \star} P<0.01\right)$. (c) Protein identified as significantly differentially expressed in W1 versus $4 A$ media. Protein: usual protein name; gene name; Peptides: number of different peptides found by mass spectrometry analyses; Coverage: percentage of related protein found by MS analyses; Mean expression ratio: fold increase (green) or decrease (orange) protein level in W1 compared with 4A CM. (d) Relative BGN mRNA expression (dRn) in 4A and W1 cells (unpaired Student's $t$-test; ${ }^{* * *} P<0.001$ ). (e) Representative western blot of BGN expression in 4A and W1 cells. (f) Representative BGN staining in PDA sections from CKI and CKITA mice, as quantified in $\mathbf{g}$ using unpaired Student's $t$-test $\left({ }^{* \star} P<0.01\right)$. Scale bars represent $100 \mu \mathrm{m}$. Error bars represent S.D.

significantly higher than that with the TAp73 wild-type

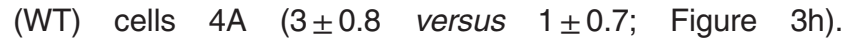
Altogether, these data highlight modifications of cellular abilities in the absence of TAp73 and confirm our previous hypothesis that TAp73-deficient cells harbor an increased EMT phenotype associated to enhanced invasiveness properties.
Secretome modulation associated to TAp73 loss leads to enhanced EMT. Considering the association of the paracrine compartment with EMT induction and maintenance, ${ }^{34}$ we investigated its involvement in the enhanced EMT observed in the absence of TAp73. Migration and invasion assays shown in Figures $4 a$ and $b$ revealed increased migration and invasion abilities of $4 \mathrm{~A}$ cells upon culturing with 
a

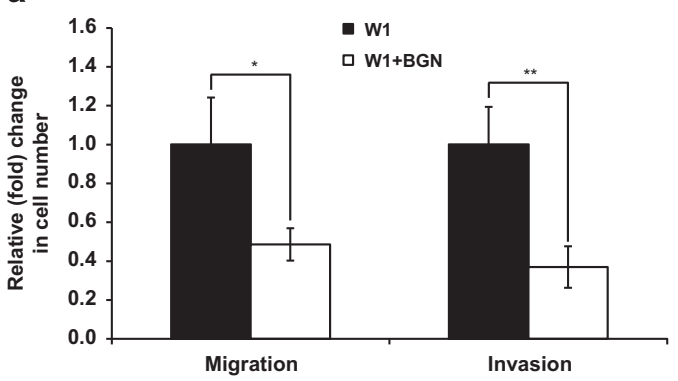

C

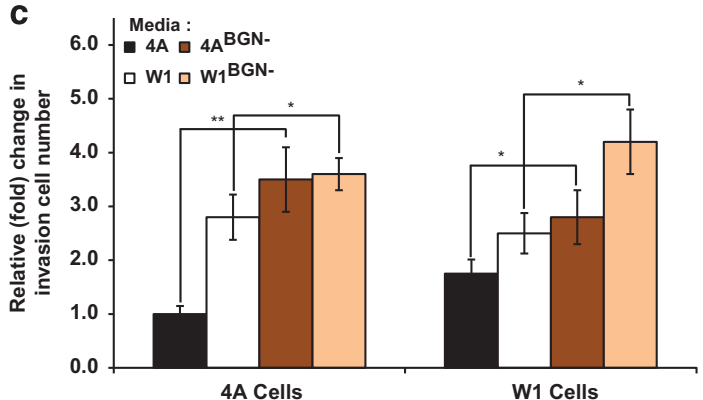

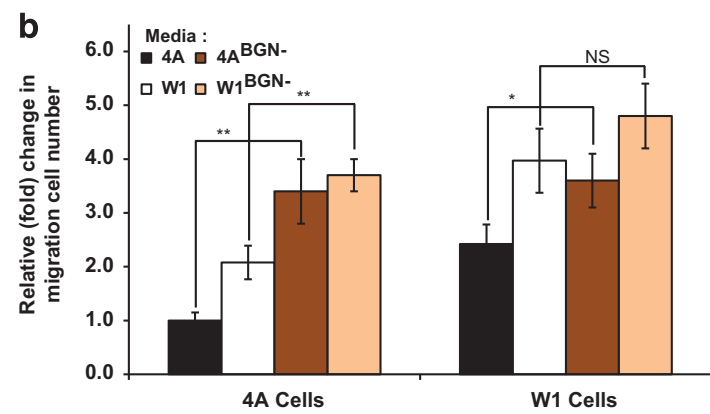

Figure 5 BGN modulates EMT-related abilities. (a) Relative (fold) change in migratory (left panel) and invasive (right panel) W1 cells upon addition of BGN recombinant protein to the CM (unpaired Student's $t$-test; ${ }^{*} P<0.05 ;{ }^{* \star} P<0.01$ ). (b) Relative (fold) change in migratory $4 \mathrm{~A}$ and $\mathrm{W} 1$ cells when cultivated with $4 \mathrm{~A}$ or W1 CM depleted or not for BGN (unpaired Student's $t$-test; ${ }^{*} P<0.05 ;{ }^{* *} P<0.01$ ). (c) Relative (fold) change in invasive $4 \mathrm{~A}$ and W1 cells when cultivated with $4 \mathrm{~A}$ or W1 CM depleted or not for BGN (unpaired Student's $t$-test; $\left.{ }^{*} P<0.05 ;{ }^{* *} P<0.01\right)$. Error bars represent S.D.

W1 media in contrast to decreased abilities shown by W1 cells upon incubation with $4 \mathrm{~A}$ media; this would suggest that secretome composition impacts EMT-associated abilities. We then analyzed the conditioned media (CM) and highlighted proteins that were decreased in the W1 CM and that had already been associated with cancer progression (Figure 4c). Among them, we focused our attention on BGN, a proteoglycan known to be a TGF- $\beta$ repressor. ${ }^{35}$ In cancer, seemingly contradicting data have revealed that increased BGN expression is linked with poor prognosis, ${ }^{36}$ whereas its overexpression was associated with inhibition of cancer cell growth. ${ }^{37,38}$ We investigated the loss of BGN in the absence of TAp73 (W1 cells) and revealed that Bgn expression was drastically reduced in TAp73-deficient cells compared with that in $4 \mathrm{~A}$ cells as well as in Panc1 cells transfected with TAp73 siRNA compared with that in Panc1 cells transfected with siCtr (Figure 4d). This suggests that Bgn, which has seven response elements for p53 family proteins according to the p53FamTaG database,${ }^{39}$ could be a direct transcriptional target of TAp73. A decreased amount of BGN was also confirmed at the protein level (Figure 4e). PDA from CKITA mice also showed similar decrease of BGN staining compared with that of PDA from CKI mice (Figures $4 \mathrm{f}$ and g). Our data confirm the loss of BGN in absence of TAp73 and suggest that it may form the link between enhanced EMT and TAp73 loss.

BGN is an EMT modulator in PDA. To determine the prominent role of BGN in the pro-EMT phenotype observed in the absence of TAp73, we first showed that recombinant BGN was able to reverse the migration and invasion abilities conferred by W1 CM (Figure 5a). The capacity of BGN to block migration and invasion was confirmed by the loss of reversal found using $4 \mathrm{~A}$ and $\mathrm{W} 1 \mathrm{CM}$ that had been BGN depleted using anti-BGN antibodies to obtain $4 \mathrm{~A}^{\mathrm{BGN}-}$ and $\mathrm{W} 1^{\mathrm{BGN}}$ - media (Figures $5 \mathrm{~b}$ and $\mathrm{c}$ ). Regarding migration ability, $4 \mathrm{~A}^{\mathrm{BGN} \text { - }}$ media was able to enhance $4 \mathrm{~A}$ cell migration (Figure $5 b$ ), further highlighting the inhibiting role of $B G N$ in migration. Interestingly, $\mathrm{W}_{1}^{\mathrm{BGN}-}$ medium was even more efficient than $\mathrm{W} 1$ media suggesting the remaining presence of a low level of BGN in the absence of TAp73. Similar results were obtained for invasion assays with $4 A^{B G N}-$ and $W 1^{B G N-}$ media both able to enhance the invasion capacity of $4 A$ cells (Figure 5c). Our data reveal that the presence of BGN in media limits EMT-related abilities of PDA cell lines.

EMT enhancement in the absence of TAp73 and BGN is associated with induction of Smad4-independent TGF- $\beta$ pathway. Regarding the above data and the well-known connection between TGF- $\beta$ and EMT, ${ }^{40}$ we hypothesized that the absence of BGN, in a TAp73-deficient context, could be related to TG-F $\beta$ pathway deregulation leading to EMT. We confirmed that TGF- $\beta$ induced Bgn expression in 4A cells and not in W1 cells (Supplementary Figure S4a), suggesting that Bgn expression, after TGF- $\beta$ treatment, is dependent on TAp73. The tumor-suppressor role of TGF- $\beta$ in pancreatic cancer is mainly mediated by SMAD4, a transcription factor, inactivated in half of invasive PDA ${ }^{41}$ and known to induce Bgn expression after TGF- $\beta$ treatment. ${ }^{42}$ Interestingly in TAp73-deficient cells, we observed a decrease in SMAD4 (Figure 6a) consistent with the presence of p53-responsive elements in all promoters of Smad genes. ${ }^{39}$ We obtained similar data in vivo with decreased protein levels of SMAD4, SMAD2 and SMAD3 in PDA from CKITA mice compared 
a

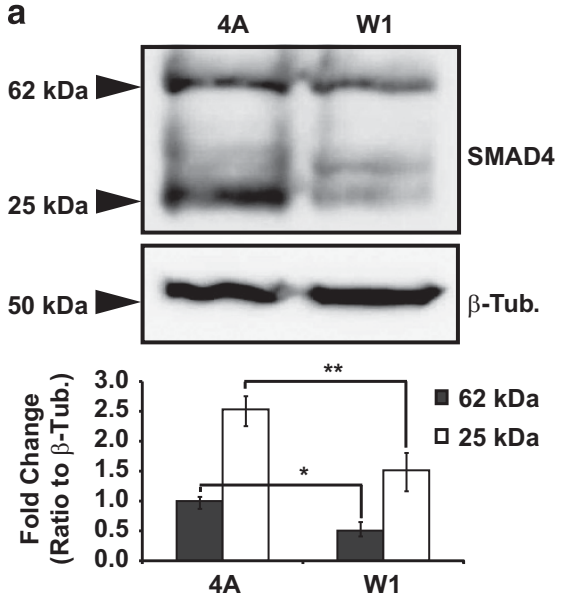

b

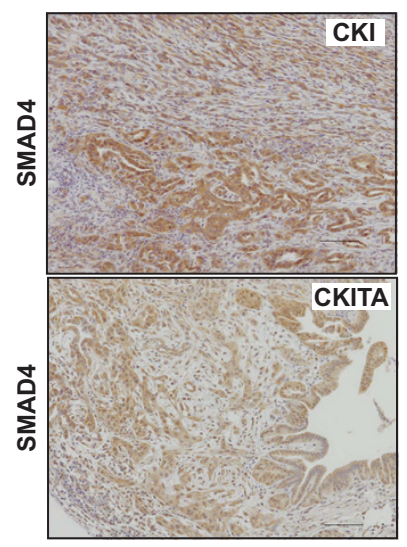

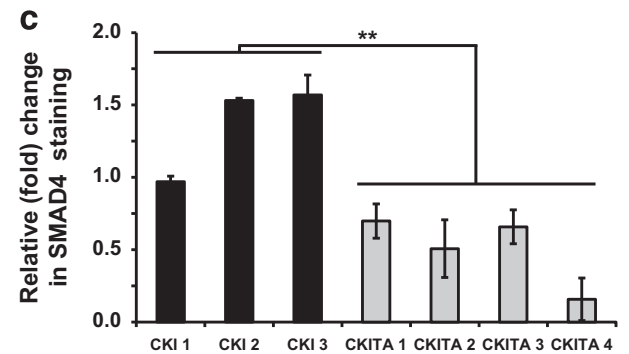

d

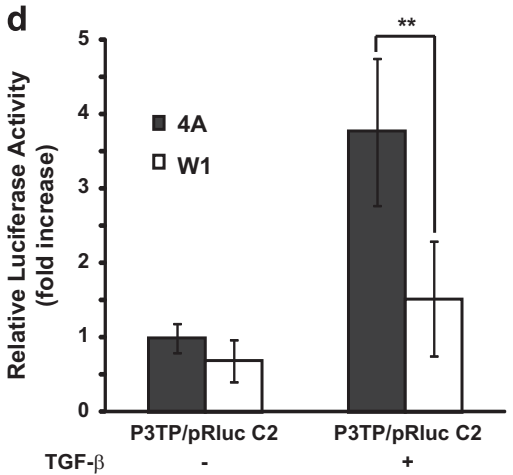

e
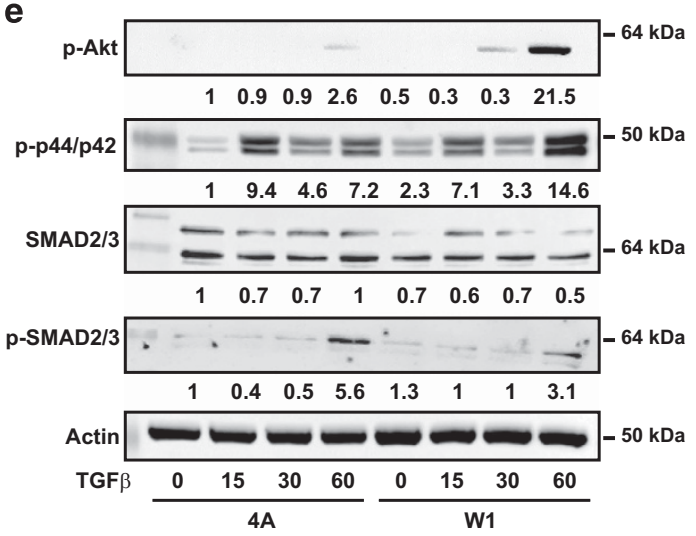

f

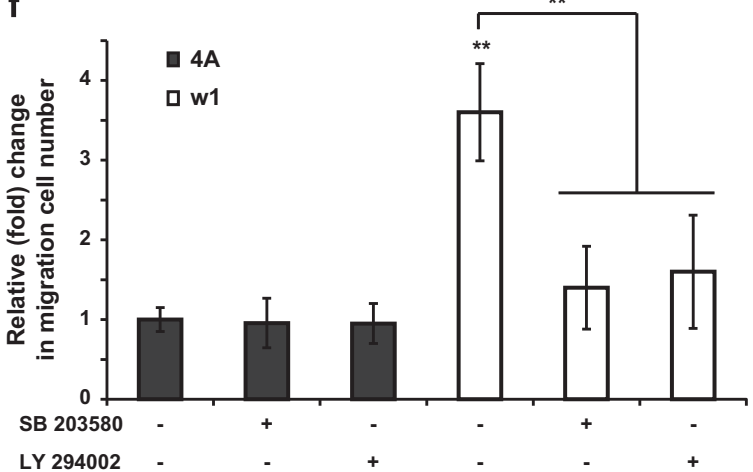

g

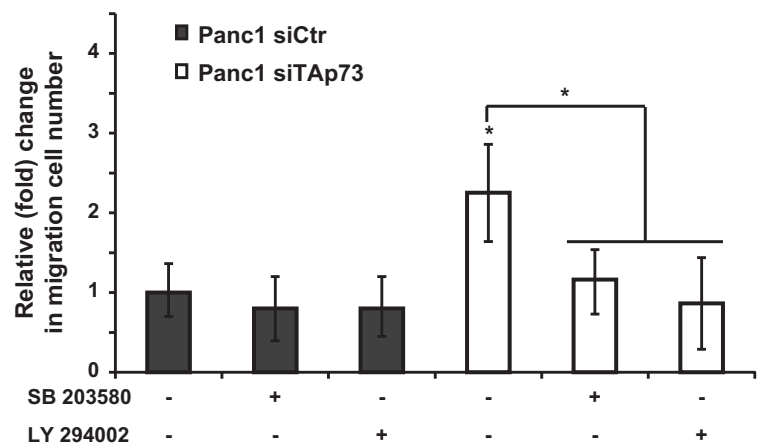

Figure 6 SMAD4 deregulation associated with TAp73 deficiency leads to EMT-related abilities. (a) Representative immunoblot of SMAD4 expression in $4 A$ and W1 cells $24 \mathrm{~h}$ after $5 \mathrm{ng} / \mathrm{ml} \mathrm{TGF-} \beta$ treatment and quantification of immunoblot from three independent experiments (unpaired Student's $t$-test; ${ }^{*} P<0.05$; ${ }^{* *} P<0.01$ ). (b) Representative SMAD4 staining in PDA sections from CKI and CKITA mice, as quantified in $\mathbf{c}$ using unpaired Student's $t$-test ( $\left.{ }^{* \star} P<0.01\right)$. Scale bars represent $100 \mu \mathrm{m}$. (d) Relative luciferase activities were measured in $4 \mathrm{~A}$ or $\mathrm{W} 1$ cell extracts, normalized to the Renilla luciferase activity. Luciferase activity is presented as fold induction relative to the basal level measured in $4 \mathrm{~A}$ cells transfected with p3TP/pRluc C2 alone without treatment. Data represent the mean \pm S.D. from three separate experiments (unpaired Student's $t$-test; ${ }^{* *} P<0.01$ ).

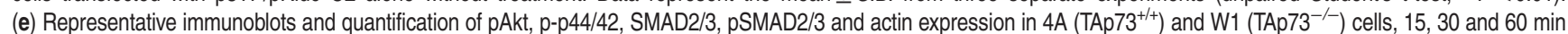
after $5 \mathrm{ng} / \mathrm{ml}$ of TGF- $\beta$ treatment. (f) and (g) Relative (fold) change in migratory 4A and W1 (f) or Panc1 siCtr and Panc1 siTAp73 (g) cells when incubated with SB203580 or LY29400 (unpaired Student's $t$-test; ${ }^{*} P<0.05 ;{ }^{*} P<0.01$ )

with CKI mice (Figures $6 \mathrm{~b}$ and c, and Supplementary Figures S4b and c). Moreover, the use of a luciferase reporter construct carrying SMAD-responsive elements revealed that TGF- $\beta$ ability to induce luciferase activity through SMAD binding in TAp73 WT cells (4A) is lost in a TAp73-deficient context (W1 cells) (Figure 6d) suggesting that TAp73 modulates TGF- $\beta$ signaling through activation of a Smad4-dependent pathway. We hypothesized that a simultaneous absence of TAp73 and the TGF- $\beta$ blocker BGN lead to a reinforced TGF- $\beta$ signaling switching to SMAD4-independent pathways. ${ }^{12,13}$ Such hypothesis was confirmed in Figure $6 \mathrm{e}$ as we could observe an induction of 
PI3K and MAPK pathways $1 \mathrm{~h}$ after TGF- $\beta$ treatment together with a decrease in pSMAD2 (Figure 6e). PI3K or MAPK pathways inhibitions, using chemical inhibitors, impaired the migration ability of murine (Figure 6f) and human (Figure 6g) TAp73-deficient cells demonstrating that activation of those pathways are necessary for the gain of migration ability in absence of TAp73. Moreover, we evaluated the responsiveness of $4 A$ and $W 1$ cells to the known SMAD4-dependent cell death after TGF- $\beta$ treatment. We observed that while $4 \mathrm{~A}$ cells are sensitive to TFG- $\beta$ treatment, cells deficient in TAp73 showed no response (Supplementary Figure S4d). ${ }^{43}$ Altogether, these data clearly suggest that the absence of TAp73 impairs TGF- $\beta$ signaling toward the tumor suppressing SMAD4-dependent pathway.

\section{Discussion}

Despite recent advances in chemotherapeutic treatments, the prognosis for PDA and its unexpected burden urgently require an expanded clinician's tool-box to change patient fate and quality of life. Achieving part of this objective, regarded by some in the scientific community as the Holy Grail, would offer a means to substantially lower pancreatic cancer incidence in the future. Inter and intra-PDA heterogeneity combined with a drastic genomic instability forces us to deepen our understanding on molecular events that drive the development and the evolution of tumor cells through critical pathways that are, at present, unusable in therapy.

Previous studies reported the p53 homolog TAp73 as involved in cancer development through cell growth/death regulatory mechanisms and more recently in tumor angiogenesis ${ }^{44}$ or metabolic adaptation. ${ }^{45}$ Interestingly, although TAp73 has gained some importance within the cancer field, the significance of its altered expression in various cancers has not yet been clearly defined in terms of its clinical translation into cancer. ${ }^{46}$ In parallel, several studies have confirmed the convergence of p53 and the TGF- $\beta$ network, ${ }^{47}$ two major cancer regulators driving multiple cancer-associated pathways. In pancreatic cancer, their interplay seems to be associated with SMADs, ${ }^{48}$ the deletion or mutation of which correlates with shorter survival and widespread metastasis. Deciphering the implication of TAp73 in PDA could enhance our knowledge on activated pathways related with SMADs activities in pancreatic cancer cells. Importantly, it could provide a means to genomically or proteomically stratify patients with a view to offering a more personalized medicine, a concrete hope in pancreatic cancer therapy. ${ }^{49}$

To investigate TAp73 implication in pancreatic carcinogenesis, we used relevant endogenous mouse models and showed that decreased survival specifically correlated with TAp73 loss, whereas p53 level/activities remained unchanged. Interestingly, similar results were obtained using a pancreatic cancer mouse model bearing an inactivated $\mathrm{p} 53,{ }^{50}$ suggesting that while both proteins are involved in controlling pancreatic carcinogenesis, TAp73 and p53 functions are not compensatory. Histological examination of TAp73-deficient PDA highlighted characteristics of EMT, which was recently proposed for use in distinguishing patients suitable for surgical resection from those requiring therapeutic intervention. ${ }^{51}$ We confirmed this pro-EMT phenotype in pancreatic cancer TAp73-deficient cell lines, by analyzing EMT-associated abilities such as enhanced migratory capacity and invasiveness as well as resistance to chemotherapeutic agent. At the molecular level, we confirmed that PDA-associated EMT markers (such as aSMA or Snail) ${ }^{52}$ were further increased in TAp73-deficient cells.

As we were interested by paracrine effects, we analyzed CM by mass spectrometry and identified several proteins associated with the EMT phenotype. Among them, we focused our attention on BGN, a protein close to the TGF- $\beta$ family that, besides its implication in multiple cancers, is induced by the TGF- $\beta$ canonical pathway downstream of SMADs signaling ${ }^{42}$ and, once the secreted form is cleaved, can favor the release of active TGF $-\beta .^{53}$ Interestingly, this increased amount of free TGF- $\beta$ is suspected to be associated with increased risk of pancreatic cancer ${ }^{54}$ as well as resistance to anticancer treatment ${ }^{55}$ and could also be responsible for the promotion of the EMT state. Although free TGF $-\beta$ can activate both SMAD-dependent and -independent pathways in WT cells, in SMAD-deficient cells it can activate only the SMAD-independent pathways, such as ERK, JNK, p38MAPK and PI3K/AKT, leading to the expression of EMT-related transcription factors such as Snail and ZEB and thus an EMT state.

Interestingly, as suggested above, absence of TAp73 also leads to in-cell modifications with decreases in SMADs levels/ activities. Thus, TAp73-deficient cells are unable to trigger activation of the SMAD-dependent pathway and upon increased levels of free TGF- $\beta$, reinforced in the absence of TGF- $\beta$ trapping by BGN, can display high levels of SMADindependent pathway activation. Moreover, the increased level of free TGF- $\beta$ can also favor immune suppression ${ }^{56}$ with an accumulation of tumor-associated macrophages, on which TAp73 deletion has been shown to impact. ${ }^{24}$ Future studies could therefore consider investigating the potential role of TAp73 in PDA-associated immune response. Altogether, our data suggest that both in-cell modifications and paracrine effects brought about by TAp73 deficiency force a switch in function of TGF- $\beta$ in carcinogenesis from tumor suppressive to tumor promoting (Figure 7), and thereby refine our understanding and clinical translation of TGF- $\beta$ modulation.

In a field requiring exploration of every possible options, attempts to optimize TGF- $\beta$ inhibition for pancreatic cancer treatment are challenging, notably with regards to patient selection, timing of treatment or predictive biomarkers. Inhibition of TGF- $\beta$ using inhibitors of TGF $-\beta$ receptors or ligands, as well as antisense oligonucleotides or small molecule receptor kinase inhibitors, are under investigations and/or in clinical trials. ${ }^{57}$ At present, the selection of patients with a more precise TGF- $\beta$-activated pathway could predict the therapeutic potential of TGF- $\beta$ targeting. ${ }^{58}$ In this line, measuring the level of TAp73 could predict which pathway, oncogenic or tumor suppressive, TGF- $\beta$ is preferentially using at a specific time for each patient.

In summary, our study depicts the impact of TAp73 loss on PDA carcinogenesis, in particular its influence on tumor aggressiveness through a TGF- $\beta$-driven pro-EMT modulation of cancer cells. Moreover, it clearly reveals a rationale for investigating the association of TAp73 expression and, as example, response to MEK inhibitors, which target 


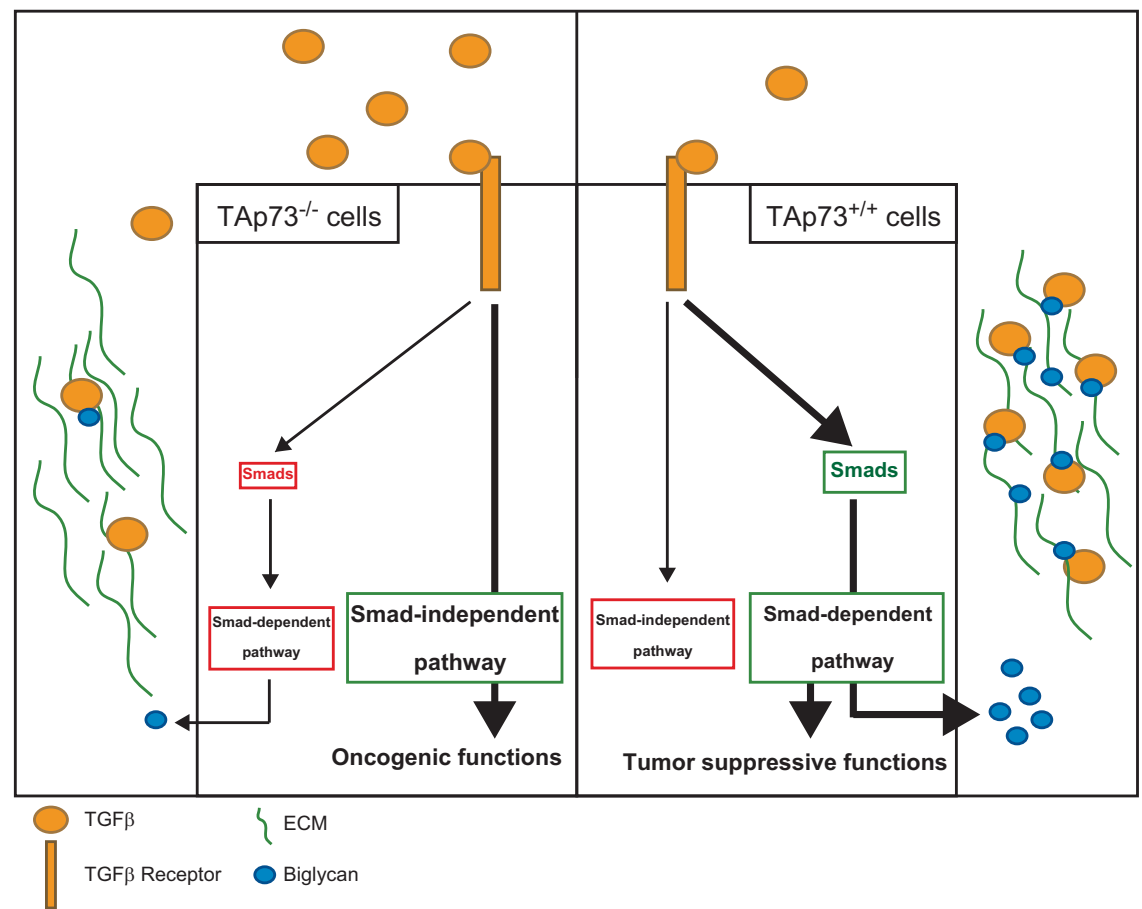

Figure 7 In the presence of TAp73 (right panel) and following TGF- $\beta$ receptor activation by TGF- $\beta$, SMAD-dependent pathway is activated, promoting tumor-suppressive functions including BGN secretion, which traps TGF- $\beta$ within the ECM. In the absence of TAp73 (left panel), the presence/activity of SMADs proteins are limited favoring, after TGF- $\beta$ stimulation, the induction of the oncogenic SMAD-independent pathway leading to EMT. As a consequence, BGN expression/secretion is reduced, limiting TGF- $\beta$ trapping within the ECM, which creates a positive loop that reinforce the oncogenic impact of SMAD-independent pathways

SMAD-independent pathways activated in PDA. Deciphering the complex SMAD-dependent and SMAD-independent TGF- $\beta$ pathways could also reveal interesting predictive biomarkers with a view to optimizing the use of TGF- $\beta$ treatment in the specific context of pancreatic cancer.

\section{Materials and Methods}

Mouse models and tumor analysis. Genetically engineered mouse strains used in our study, containing a floxed Ink4a/Arf, Kras ${ }^{\text {LL-G12D }}$ and Pdx1-cre alleles were kindly provided by Ronald Depinho's laboratory (Boston, MA, USA). These strains were interbred to generate the PDA mouse model Pdx1-Cre; $\mathrm{Kras}^{\text {LSL-G12D Ink4a/Arf }}{ }^{\mathrm{F} / F} ; \mathrm{TAp}^{+/++}$. Mutant mice deficient for Trp73 exons 2 and 3 , which are specific for the TAp73 isoforms, were generated by conventional gene targeting procedures as previously described. ${ }^{19}$ CKI or TAp73 WT (Pdx1-Cre; Kras $^{\text {LSL-G12D Ink4a/Arf }}$ F/F; TAp73 $3^{+/+}$) and CKITA or TAp73 knockout (Pdx1-Cre;

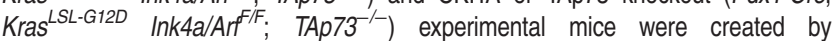
intercrossing Pdx1-Cre; Ink4a/Arf ${ }^{F /+}$; TAp73 ${ }^{+/-}$mice with $\mathrm{Kras}^{\mathrm{LLL}-\mathrm{G} 12 \mathrm{D} ;}$; Ink4a/Arf ${ }^{\mathrm{F} /+}$; $\mathrm{TAp}^{+/-}$mice. CKIH and CKIHTA mice were generated by intercrossing Pdx1-Cre;

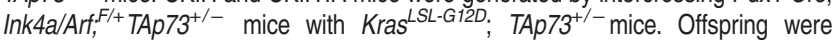
genotyped by PCR analysis using specific primer pairs to detect the WT Trp73 and $\operatorname{Trp} 73^{\Delta T A}$ alleles. Primers for Trp73 allele were $5^{\prime}$-CTGGTCCAGGAGGTGAGA CTGAGGC-3', 5'-CTGGCCCTCTCAGCTTGTGCCACTTC-3'. Primers for Trp73 ${ }^{4 T A}$ allele were $5^{\prime}$-GTGGGGGTGGGATTAGATAAATGCCTG-3' and $5^{\prime}$-CTGGCCCTC TCAGCTTGTGCCACTTC-3'. Life span and spontaneous tumor incidence were determined in TAp73 WT and TAp73 knockout mice. Tumors and tissues of control and mutant mice were collected and processed for histopathology and DNA isolation by standard procedures.

PDA orthotopic xenograft model. Under isoflurane anesthesia (induction: $4 \%$ (vol/vol) and maintenance: $1.5 \%$ (vol/vol)), 5-week-old male NMRI nude mice (Harlan, Gannat, France) were intra-pancreatically injected with $0.5 \times 10^{6} 4 \mathrm{~A}$ or W1 cells. After 4 weeks of growth, tumor volume was established with the following formula: $\left(L \times W^{2}\right) / 2$; tumor weight was measured and number of liver metastases was determined.

Study approval. Mice were cared for and manipulated in accordance with National and European legislation on animal experimentation and the experimental design was approved by the Aix-Marseille University Institutional Animal Care and Use Committee (CE2A-14).

Cell culture. Cell lines were developed from tumors of TAp73 WT and TAp73 knockout mice as previously described. ${ }^{59}$ Cells were cultured in DMEM/F-12 (Life Technologies, Saint-Aubin, France), $1.22 \mathrm{mg} / \mathrm{ml}$ nicotinamide (Sigma-Aldrich, Lille-Lezennes, France), $5 \mathrm{mg} / \mathrm{ml}$ glucose (Sigma-Aldrich), $5 \%$ ITS+ (BD Biosciences, Le pont de Claix, France), $100 \mu \mathrm{g} / \mathrm{ml}$ gentamicin (Life Technologies), 1x fungizone (Life Technologies), 5\% Nu-serum IV (BD Biosciences), $25 \mu \mathrm{g} / \mathrm{ml}$ BPE (Life Technologies), 20 ng/ml EGF (BD Biosciences), 50 nM 3,3',5-triiodo-Lthyronine (Sigma-Aldrich), $1 \mu \mathrm{g}$ dexamethasone (Sigma-Aldrich), and $100 \mathrm{ng} / \mathrm{ml}$ cholera toxin (Sigma-Aldrich). After 10 passages, cell culture medium was replaced by DMEM (Life Technologies) supplemented with 10\% FBS (Sigma-Aldrich). Cell lines were genotyped by PCR analysis using above-mentioned primer pairs to confirm the WT Trp73 and Trp73 ${ }^{\triangle T A}$ alleles. siRNA used for TAp73 downregulation were done as previously mentioned. ${ }^{20}$

TGF- $\boldsymbol{\beta} 1$ treatment. Cells were incubated for 12 or $24 \mathrm{~h}$ with various concentrations $(0,1$ or $5.0 \mathrm{ng} / \mathrm{ml}$ ) of mouse TGF- $\beta 1$ (mTGF- $\beta 1$; Cell Signaling Technology, Beverly, MA, USA) before being continually cultured for different time periods in growth medium. Differentially treated cells were finally used for various cell studies.

Proliferation. Proliferation assay was performed by 3-(4,5-dimethylthiazol-2-yl)2,5-diphenyl tetrazolium bromide (MTT) assay and direct cell counting. TAp73 WT and knockout cells were plated at a density of $5 \times 10^{4}$ cells $/ \mathrm{ml} 10 \%$ FBS, DMEM in 96-well plates for 24, 48 and $72 \mathrm{~h}$. In all, $20 \mu \mathrm{l}$ MTT solution ( $5 \mathrm{mg} / \mathrm{ml}$ ) was added to 
each well. After $30-$ min incubation at $37^{\circ} \mathrm{C}$, the absorbance was measured by ELx808 Microplate Reader (Biotek, Colmar, France).

Apoptosis assay. Apoptosis assay was performed using the caspase- $3 / 7 \mathrm{glow}$ assay kit (Promega, Charbonnières-les-Bains, France). Cells were plated at a density of $5 \times 10^{4}$ cells per well in 10\% FBS, DMEM in 96-well plates and treated with $5 \mu \mathrm{M}$ gemcitabine for 24,48 and $72 \mathrm{~h}$ or treated with $5 \mathrm{ng} / \mathrm{ml}$ TGF- $\beta$ for $24 \mathrm{~h}$. Equal volumes of caspase-3/7 glow reagent was added to each well before incubation at room temperature. Luminescence was recorded using the Tristar LB-941 (Berthold Technologies, Thoiry, France).

Conditioned media. CM were obtained after serum deprivation and production for $24 \mathrm{~h}$. Cells were seeded at a density of 50000 cells $/ \mathrm{cm}^{2}$ in DMEM, $10 \%$ FBS, $1 \%$ antibiotic-antimycotic (Life Technologies). After 24-h incubation, cells were washed three times with PBS $1 \mathrm{x}$ and growth medium was replaced with DMEM without serum. Cells were incubated for $24 \mathrm{~h}$ at $37^{\circ} \mathrm{C}$ in $\mathrm{CO}_{2}$ incubator. Media were removed and centrifuged to remove cell debris if any before being used for mass spectrometry, migration assays and invasion assays.

Migration assay. Briefly, a 24-well cell culture chamber (BD Biosciences) was used and polycarbonate membrane inserts of $8 \mu \mathrm{m}$ pore size were precoated with $10 \mu \mathrm{g} / \mathrm{ml}$ of human plasma fibronectin (Sigma-Aldrich) and $0.1 \%$ porcine gelatin (Sigma-Aldrich) PBS $1 \times$ overnight at $4^{\circ} \mathrm{C}$. As chemoattractant for cell migration, $700 \mu \mathrm{l}$ of $\mathrm{CM}$ was added in each well. Cells were washed and trypsinized before being rinsed three times with PBS $1 \times$. In all, $1 \times 10^{5}$ cells suspended in $200 \mu$ l of DMEM without FBS were seeded in the upper compartment after placing the inserts in chamber wells. Cells were allowed to migrate for $4 \mathrm{~h}$ at $37^{\circ} \mathrm{C}$ in a humidified chamber with $5 \% \mathrm{CO}_{2}$. After incubation, the inserts were removed and the upper side of the insert containing cells that did not migrate was scraped with a cotton swab. The filters were fixed with methanol and stained with $1 \%$ crystal violet. Migration was quantified by counting all the cells in each well. Visualization was achieved with an inverted Olympus IX70 microscope (Rungis, France) and pictures were taking with a Carl Zeiss AxioCam (Carl Zeiss GmbH, Jena, Germany). All groups were studied in triplicate and the experiment repeated three times. For BGN depletion: CM was incubated with $10 \mu \mathrm{l}$ of anti-BGN serum for $2 \mathrm{~h}$. After incubation, $50 \mu$ of protein G pre-equilibrated with 1x PBS was added before 30-min incubation. Protein-G was removed by centrifugation for 1 min at 10000 r.p.m. and depleted CM were recovered.

Invasion assay. Invasion assays were performed by growing the cells on matrigel in Petri dishes and by using invasion chambers. In all, $2 \times 10^{3}$ cells in DMEM, $10 \%$ FBS were mixed to a ratio of $1: 3$ with matrigel before being poured onto Petri dishes. Plates were incubated for $72 \mathrm{~h}$ at $37^{\circ} \mathrm{C}$ and observed under a microscope. Cell invasion assays were performed using Cell Invasion Chambers (BD Biosciences), containing an $8 \mu \mathrm{m}$ pore size PET membrane with a thin layer of Matrigel basement membrane matrix. In all, $700 \mu \mathrm{l}$ CM was used as chemoattractant. The invasion procedure was similar to that used in the migration assay with an incubation time of $22 \mathrm{~h}$ and $1 \times 10^{5}$ cells suspended in $500 \mu \mathrm{l}$ of DMEM without FBS were seeded in the upper compartment. All the cells were counted in each well as described in the migration assay.

Sample preparation and peptide fractionation. In all, $40 \mathrm{ml}$ of $\mathrm{CM}$ were desalted using Amicon Ultra $5 \mathrm{~K}$ centrifugal filter device (Millipore, Molsheim, France). Concentrated sample buffer was exchanged three times in $100 \mathrm{mM}$ triethylammonium bicarbonate. Samples were reduced with $5 \mathrm{mM}$ Tris-(2carboxyethy) phosphine (Sigma-Aldrich) at $60^{\circ} \mathrm{C}$ for $60 \mathrm{~min}$, alkylated with $55 \mathrm{mM}$ iodoacetamide (Sigma-Aldrich) at room temperature (in dark) for $30 \mathrm{~min}$, and digested overnight at $37^{\circ} \mathrm{C}$ with $3: 100$ W/W sequencing grade modified porcine trypsin (Promega). In all, $90 \mu \mathrm{g}$ of the digests were dried in a Speedvac concentrator (Thermo Fisher Scientific, Waltham, MA, USA) and labeled with iTRAQ reagent 115 or 116 according to the standard protocol supplied by the manufacture (AB SCIEX, Les Ulis, France). After labeling, samples were pooled and dried with speedvac before the peptide fractionation according to their pl. To perform peptide fractionation, 3100 OFFGEL Fractionator and the low resolution OFFGEL Kit 3-10 (linear $\mathrm{pH}$ gradient, 12 fractions) from Agilent Technologies (Massy, France) were used following the user's guide protocol. After focusing, each fraction was transferred in microtubes and concentrated by Speedvac before LC-MS/MS analysis.
Liquid chromatography-electrospray ionization MS/MS and data analysis. Speedvac-dried peptide extracts were resuspended in 15 to $80 \mu \mathrm{l}$ of $3 \%(v: v)$ acetonitrile/0.1\% (v:v) formic acid and then analyzed with a nano-LC1200 system coupled to a Q-TOF 6520 mass spectrometer equipped with a nanospray source and an HPLC-chip cube interface (Agilent Technologies). Briefly, peptides were enriched and desalted on a $160 \mathrm{nl}$ RP-C18 trap column and separated on a Zorbax (30-nm pore size, 5-Im particle size) C18 column (150 mm long $75 \mathrm{Im}$ inner diameter; Agilent Technologies). A 55-min linear gradient (3-75\% acetonitrile in $0.1 \%$ formic acid) at a flow rate of $400 \mathrm{n} / / \mathrm{min}$ was used. Full autoMS1 scans from 290 to $2400 \mathrm{~m} / \mathrm{z}$ and autoMS2 from 59 to $3200 \mathrm{~m} / \mathrm{z}$ were recorded. In every cycle, a maximum of five precursors sorted by charge state (2+ preferred and singlecharged ions excluded) were isolated and fragmented in the collision cell. Collision cell energy was automatically adjusted depending on the $\mathrm{m} / \mathrm{z}$. Active exclusion of these precursors was enabled after 1 spectra within $0.2 \mathrm{~min}$, and the threshold for precursor selection was set to 1000 counts. Peptide and protein identification were performed using the Spectrum Mill software (Rev A.03.03.084 SR4; Agilent Technologies). The following parameters were used for data extraction: $\mathrm{MH}+$ mass range from 600 to 4000 , scan time range from 0 to $300 \mathrm{~min}$, similarity merging of scan with same precursor $( \pm 15 \mathrm{~s}$ and $0.05 \mathrm{~m} / \mathrm{z})$ and minimum MS s/n set to 25 . The searches were performed with the following specific parameters: enzyme specificity, trypsin; two missed cleavage permitted; iTRAQ ( $\mathrm{N}$-term, K) fixed modifications; variable modifications, methionine oxidation, cysteine carbamidomethylation and Gln pyro-Glu (N-ter Q); maximum ambiguous precursor charge set to 3; mass tolerance for precursor ions, 20 p.p.m.; mass tolerance for fragment ions, 50 p.p.m.; ESI-QUAD-TOF as instrument; taxonomy, Mus muculus; database, Swissprot downloaded December 2010; 50\% minimum scored peak intensity; calculate reversed database scores and dynamic peak thresholding. Identified proteins and peptides were autovalidated with default parameters. Validated peptides were then exported in a.ssv excel file using the following filter parameters: score of peptide $>6$ and $\%$ of SPI $>60$. Finally, differential protein expression of iTRAQ labeling data was performed using the iQuantitator open source software and the eDesign default parameter value. ${ }^{60}$

Western blot analysis. Protein extraction was performed on ice using total protein extraction buffer: $50 \mathrm{mM}$ HEPES pH 7.5, $150 \mathrm{mM} \mathrm{NaCl}, 20 \%$ SDS, $1 \mathrm{mM}$ EDTA, $1 \mathrm{mM}$ EGTA, 10\% glycerol, $1 \%$ Triton, $25 \mathrm{mM} \mathrm{NaF}, 10 \mu \mathrm{M} \mathrm{ZnCl} 2,50 \mathrm{mM}$ DTT. Before lysis, a protease inhibitor cocktail at 1:200 (Sigma-Aldrich, NUPR1340), $500 \mu \mathrm{M}$ PMSF, $1 \mathrm{mM}$ sodium orthovanadate and $1 \mathrm{mM} \beta$-glycerophosphate were added. Protein concentration was measured using a Bradford Assay. Protein samples $(100 \mu \mathrm{g})$ were denatured at $95^{\circ} \mathrm{C}$ and subsequently separated by $12.5 \%$ SDS-PAGE gel electrophoresis. After transfer to nitrocellulose membrane and blocking with $5 \%$ milk, samples were probed with the following antibodies: rabbit polyclonal anti-mouse BGN LF-106 was a generous gift from Dr. Larry W Fisher, Bethesda, MD, USA ${ }^{57}(1 / 100)$, rabbit monoclonal anti-Smad4 (Epitomics, Burlingame, CA, USA, 1/500), rabbit monoclonal pAkt (9271, Cell Signaling Technology, 1/500), rabbit monoclonal pSMAD2/3 (3101, Cell Signaling Technology, 1/500), rabbit monoclonal SMAD2/3 (3102, Cell Signaling Technology, 1/500), rabbit monoclonal p44/42 (4376, Cell Signaling Technology, 1/500), mouse $\beta$-tubulin (Sigma-Aldrich), rabbit polyclonal to N-cadherin (Abcam, Cambridge, Great-Britain, Ab18203, 1/400), goat polyclonal to ZEB1 (sc-10572, Santa Cruz, Nanterre, France, 1/100), rabbit polyclonal to SNAIL (ab-180714, Abcam, 1/100), mouse monoclonal anti-vimentin (Sigma-Aldrich, V6389, 1/100) and mouse monoclonal anti-E-cadherin (Life Technologies, 13-1900, 1/800). HRP-conjugated goat anti-mouse and goat anti-rabbit secondary antibodies and Immobilon Western Chemiluminescent HRP Substrate (Millipore) were used for detection.

RNA extracts/real-time qRT-PCR. Total cellular RNA was isolated using the Trizol protocol (Invitrogen, Cergy Pontoise, France) and cDNAs were prepared from $1 \mu \mathrm{g}$ total RNA using the ImProm-II kit (Promega) following the manufacturer's instructions. Quantitative PCR was performed in a LightCycler (Roche Diagnostics, Meylan, France) using the SYBR Premix Ex Taq (Takara Bio, Lonza, LevalloisPerret, France). Primer sets used for SYBR green-based real-time PCR were as follows: BGN primer sequences obtained from PrimerBank (Harvard Medical School) with IDs 20137008a1.

SMAD4 activity. Luciferase reporter plasmids, SBE-luc and P3TPprluc were prepared as described previously. ${ }^{61}$ Cells were plated at $70 \%$ confluence in six-well plates and $24 \mathrm{~h}$ later transiently transfected with $3 \mu \mathrm{g}$ total DNA using Lipofectamine transfection reagent (Invitrogen). In all, $5 \mathrm{ng} / \mathrm{ml}$ mTGF- $\beta 1$ was added $24 \mathrm{~h}$ later and 
left to incubate for an additional $12 \mathrm{~h}$. Coelenterazine and Luciferase reagent (Promega) were used as substrates and the assay was performed as per the manufacturer's protocol.

Histology and immunohistochemistry. Pancreatic sections were fixed in $4 \%$ paraformaldehyde and paraffin embedded. H\&E, Masson Trichrome staining and immunohistochemistry $(\mathrm{IHC})$ were performed using standard procedures. Antibodies used for IHC were: aSMA (Sigma-Aldrich, A2547, 1/200), N-cadherin (Abcam, Ab18203, 1/75), E-cadherin (Life Technologies, 13-1900, 1/400), Snail (Abcam, Ab70983, 1/100), Ki67 (Biolegend, San Diego, CA, USA, 652402, 1/100), BGN (LF-106, 1/100), Smad4 (Epitomics, EP618Y, 1/75) and Smad2/3 (Cell Signaling Technology, 3102, 1/100).

Cell cycle analysis. For cell cycle analysis, cells were harvested following $12 \mathrm{~h}$ of TGF- $\beta 1$ treatment. Cells were fixed by incubation with $70 \%$ ethanol at $4{ }^{\circ} \mathrm{C}$ for $30 \mathrm{~min}$. Subsequent to equilibrating to room temperature, the cells were washed with citrate phosphate buffer and treated with $0.05 \%$ RNase and then stained with $5 \mu \mathrm{g} / \mathrm{ml}$ propidium iodine at $4{ }^{\circ} \mathrm{C}$ for $30 \mathrm{~min}$. Following this, cell cycle experiments were performed using a FACSCalibur (BD Biosciences) and data were analyzed using FlowJo software (Ashland, OR, USA).

Statistics. Error bars indicate \pm S.D. in each figures except for Figure $3 \mathrm{~h}$ where it represents \pm S.E.M. between biological replicates. Technical as well as biological triplicates of each experiment were performed. Statistical significance was determined using the unpaired two-tailed Student's $t$-test, except for multiplegroup comparisons, for which significance was determined using a one-way ANOVA with GraphPad Prism (GraphPad Software, La Jolla, CA, USA). A P-value $\leq 0.05$ was considered significant. Cumulative survival time was calculated by the KaplanMeier method and analyzed by the log-rank (Mantel-Cox) test. $P<0.05$ was considered statistically significant.

Study of the TP73 gene copy number in pancreatic cancer. Fourteen consecutive pancreatic cancer samples were obtained by endoscopic ultrasound (EUS)-guided fine needle aspiration cytology between June 2007 and September 2007 at Hôpital Nord, Marseille. Written informed consent was obtained from all participants. Six samples were obtained from patients without detectable metastasis whereas eight presented metastases at the time of the sampling. DNA was extracted, amplified and hybridized on Affymetrix Genome-Wide human SNP array 6.0 according to the manufacturer's instructions (Affymetrix Inc., Santa Clara, CA, USA). The Affymetrix Genome-Wide Human SNP Array 6.0 features $>1.8$ million markers of genetic variation, including $>906600$ single-nucleotide polymorphisms (SNPs) and $>946000$ probes for the detection of CNV. The median inter-marker distance taken over all 1.8 million SNP and copy number markers combined is 696 bases. The array also contains 202000 probes targeting 5677 known regions of CNV, resolved into 3182 distinct, non-overlapping segments, from the Toronto Database of Genomic Variants. Hybridization, washing, staining and chip scanning were performed by the CRCHUL microarray Core Facility using materials and methods provided by the manufacturer (Affymetrix Inc.). Overall hybridization quality was estimated by the call rate index obtained from GeneChip Genotyping Analysis Software (GTYPE, birdseed algorithm using default parameter settings). Allelic ratios were calculated with the Partek Genomics Suite, version 6.4 (Partek Inc., St. Louis, MO, USA) using the proprietary default parameters. A 270 HapMap sample collection was used to create copy number from baseline. Genomic segmentation was utilized as a method to detect copy number alterations. Regions were detected using the following segmentation parameters: minimum of 10 genomic markers; segmentation $P$-value threshold lower than 0.001 ; and a signal to noise equal to 0.3 . Using these parameters, 10263 segments were detected. Selected segments were visualized in a genomic context with the Partek Genomics Suite.

\section{Conflict of Interest}

The author declare no conflict of interest.

Acknowledgements. We thank Patricia Spoto, Bruno Olivier, Laurence Borge, Karim Sari and Régis Vitestelle from INSERM U1068 for their technical assistance or scientific advice. We also thank the U1068 Cell Culture Platform (Luminy, Marseille, France) as well as the Animal colony facility platform 'PSEA' (Luminy, Marseille,
France). The research leading to these results received funding from 'AMU, AixMarseille University' (to AKT and SL), SIRIC PACA-OUEST (grant INCa-DGOSInserm 6038), the 'Association de Recherche contre le cancer' (ARC) and from the European Research Council under the European Union's Seventh Framework Program (FP/2007-2013)/ERC grant agreement no. (282036)

1. Chiang KC, Yeh CN, Ueng SH, Hsu JT, Yeh TS, Jan YY et al. Clinicodemographic aspect of resectable pancreatic cancer and prognostic factors for resectable cancer. World J Surg Oncol 2012; 10: 77-86.

2. Rahib L, Smith BD, Aizenberg R, Rosenzweig AB, Fleshman JM, Matrisian LM. Projecting cancer incidence and deaths to 2030: The unexpected burden of thyroid, liver and pancreas cancers in the united States. Cancer Res 2014; 74: 2913-2921.

3. Xu Z, Pothula SP, Wilson JS, Apte MV. Pancreatic cancer and its stroma: a conspiracy theory. World J Gastroentero 2014; 20: 11216-11229.

4. Inman KS, Francis AA, Murray NR. Complex role for the immune system in initiation and progression of pancreatic cancer. World J Gastroentero 2014; 20: 11160-11181.

5. Hamada S, Masamune A, Shimosegawa T. Novel therapeutic strategies targeting tumorstromal interactions in pancreatic cancer. Front Physiol 2013; 4: 331.

6. Maréchal R, Bachet JB, Calomme A, Demetter P, Delpero JR, Surcek M et al. Sonic Hedgehog and Gli1 expression predict outcome in resected pancreatic adenocarcinoma. Clin Cancer Res 2014; 21: 1215-1224.

7. García-Pravia C, Galván JA, Gutiérrez-Corral N, Solar-García L, García-Pérez E, García-Ocaña $\mathrm{M}$ et al. Overexpression of $\mathrm{COL11A1}$ by cancer-associated fibroblasts: clinical relevance of a stromal marker in pancreatic cancer. PLoS One 2013; 8: e78327.

8. Martínez-Bosch N, Fernández-Barrena MG, Moreno M, Ortiz-Zapater E, Munné-Collado J, Iglesias $\mathrm{M}$ et al. Galectin-1 drives pancreatic carcinogenesis through stroma remodeling and Hedgehog signaling activation. Cancer Res 2014; 74: 3512-3524

9. Provenzano PP, Cuevas C, Chang AE, Goel VK, Von Hoff DD, Hingorani SR. Enzymatic targeting of the stroma ablates physical barriers to treatment of pancreatic ductal adenocarcinoma. Cancer Cell 2012; 21: 418-429.

10. Inman GJ. Switching TGFbeta from a tumor suppressor to a tumor promoter. Curr Opin Genet Dev 2011; 21: 93-99.

11. Principe DR, Doll JA, Bauer J, Jung B, Munshi HG, Bartholin L et al. TGF- $\beta$ : duality of function between tumor prevention and carcinogenesis. J Natl Cancer Inst 2014; 106: djt369.

12. Izeradjene K, Combs C, Best M, Gopinathan A, Wagner A, Grady WM et al. Kras(G12D) and Smad4/Dpc4 haploinsufficiency cooperate to induce mucinous cystic neoplasms and invasive adenocarcinoma of the pancreas. Cancer Cell 2007; 11: 229-243.

13. Zhang YE. Non-Smad pathways in TGF-beta signaling. Cell Res 2009; 19: 128-139.

14. Ai X, Wu Y, Zhang W, Zhang Z, Jin G, Zhao J et al. Targeting the ERK pathway reduces liver metastasis of Smad4-inactivated colorectal cancer. Cancer Biol Ther 2013; 14: 1059-1067.

15. Krautz $C$, Rückert F, Saeger HD, Pilarsky $C$, Grützmann R. An update on molecular research of pancreatic adenocarcinoma. Anticancer Agents Med Chem 2011; 11: 411-417.

16. Guo M, Jia Y, Yu Z, House MG, Esteller M, Brock MV et al. Epigenetic changes associated with neoplasms of the exocrine and endocrine pancreas. Discov Med 2014; 17: 67-73.

17. Allocati N, Di llio C, De Laurenzi V. p63/p73 in the control of cell cycle and cell death. Exp Cell Res 2012; 318: 1285-1290.

18. Levine AJ, Tomasini R, McKeon FD, Mak TW, Melino G. The p53 family: guardians of maternal reproduction. Nat Rev Mol Cell Biol 2011; 12: 259-265.

19. Tomasini R, Tsuchihara K, Wilhelm M, Fujitani M, Rufini A, Cheung CC et al. TAp73 knockout shows genomic instability with infertility and tumor suppressor functions. Genes Dev 2008; 22: 2677-2691.

20. Tomasini R, Tsuchihara K, Tsuda C, Lau SK, Wilhelm M, Ruffini A et al. TAp73 regulates the spindle assembly checkpoint by modulating BubR1 activity. Proc Natl Acad Sci USA 2009; 106: 797-802.

21. Katayama H, Wang J, Treekitkarnmongkol W, Kawai H, Sasai K, Zhang $\mathrm{H}$ et al. Aurora kinase-A inactivates DNA damage-induced apoptosis and spindle assembly checkpoint response functions of p73. Cancer Cell 2012; 21: 196-211.

22. Loukopoulos P, Shibata T, Katoh H, Kokubu A, Sakamoto M, Yamazaki K et al. Genomewide array-based comparative genomic hybridization analysis of pancreatic adenocarcinoma: identification of genetic indicators that predict patient outcome. Cancer Sci 2007; 98: 392-400.

23. Weissmueller S, Manchado E, Saborowski M, Morris JP 4th, Wagenblast E, Davis CA et al. Mutant p53 drives pancreatic cancer metastasis through cell-autonomous PDGF receptor $\beta$ signaling. Cell 2014; 157: 382-394.

24. Tomasini R, Secq V, Pouyet L, Thakur AK, Wilhelm M, Nigri $\mathrm{J}$ et al. TAp73 is required for macrophage-mediated innate immunity and the resolution of inflammatory responses. Cell Death Diff 2013; 20: 293-301.

25. Wang Z, Ali S, Banerjee S, Bao B, Li Y, Azmi AS et al. Activated K-Ras and INK4a/Arf deficiency promote aggressiveness of pancreatic cancer by induction of EMT consistent with cancer stem cell phenotype. J Cell Physiol 2013; 228: 556-562.

26. Feldmann G, Habbe N, Dhara S, Bisht S, Alvarez H, Fendrich V et al. Hedgehog inhibition prolongs survival in a genetically engineered mouse model of pancreatic cancer. Gut 2008; 57: $1420-1430$. 
27. Bardeesy N, Aguirre AJ, Chu GC, Cheng KH, Lopez LV, Hezel AF et al. Both p16(Ink4a) and the p19(Arf)-p53 pathway constrain progression of pancreatic adenocarcinoma in the mouse. Proc Natl Acad Sci USA 2006; 103: 5947-5952.

28. Funamizu N, Hu C, Lacy C, Schetter A, Zhang G, He P et al. Macrophage migration inhibitory factor induces epithelial to mesenchymal transition, enhances tumor aggressiveness and predicts clinical outcome in resected pancreatic ductal adenocarcinoma. Int J Cancer 2012; 132: $785-794$

29. Karamitopoulou E. Role of epithelial-mesenchymal transition in pancreatic ductal adenocarcinoma: is tumor budding the missing link? Front Oncol 2013; 3: 221.

30. Nakajima S, Doi R, Toyoda E, Tsuji S, Wada M, Koizumi M et al. N-cadherin expression and epithelial-mesenchymal transition in pancreatic carcinoma. Clin Cancer Res 2004; 10: 4125-4133.

31. Salnikov AV, Liu L, Platen M, Gladkich J, Salnikova O, Ryschich E et al. Hypoxia induces EMT in low and highly aggressive pancreatic tumor cells but only cells with cancer stem cell characteristics acquire pronounced migratory potential. PLoS One 2012; 7: e46391.

32. Pinho AV, Rooman I, Real FX. p53-dependent regulation of growth, epithelial-mesenchymal transition and stemness in normal pancreatic epithelial cells. Cell Cycle 2011; 10: 1312-1321.

33. Voutsadakis IA. Molecular predictors of gemcitabine response in pancreatic cancer. World $\mathrm{J}$ Gastro Oncol 2011; 3: 153-164.

34. Scheel C, Eaton EN, Li SH, Chaffer CL, Reinhardt F, Kah KJ et al. Paracrine and autocrine signals induce and maintain mesenchymal and stem cell states in the breast. Cell 2011; 145 926-940.

35. Groth $\mathrm{S}$, Schulze M, Kalthoff $\mathrm{H}$, Fändrich $\mathrm{F}$, Ungefroren $\mathrm{H}$. Adhesion and Rac1-dependent regulation of biglycan gene expression by transforming growth factor-beta. Evidence for oxidative signaling through NADPH oxidase. J Biol Chem 2005; 280: 33190-33199.

36. Gu X, Ma Y, Xiao J, Zheng H, Song C, Gong Y et al. Up-regulated biglycan expression correlates with the malignancy in human colorectal cancers. Clin Exp Med 2012; 12: 195-199.

37. Weber CK, Sommer G, Michl P, Fensterer H, Weimer M, Gansauge F et al. Biglycan is overexpressed in pancreatic cancer and induces $\mathrm{G1}$-arrest in pancreatic cancer cell lines. Gastroenterology 2001; 121: 657-667.

38. Niedworok C, Röck K, Kretschmer I, Freudenberger T, Nagy N, Szarvas T et al. Inhibitory role of the small leucine-rich proteoglycan biglycan in bladder cancer. PLoS One 2013; 8 e80084.

39. Sbisà E, Catalano D, Grillo G, Licciulli F, Turi A, Liuni $S$ et al. p53FamTaG: a database resource of human p53, p63 and p73 direct target genes combining in silico prediction and microarray data. BMC Bioinformat 2007; 8: S20.

40. Hiraga R, Kato M, Miyagawa S, Kamata T. Nox4-derived ROS signaling contributes to TGF$\beta$-induced epithelial-mesenchymal transition in pancreatic cancer cells. Anticancer Res 2013; 33: 4431-4438

41. Bardeesy N, Cheng KH, Berger JH, Chu GC, Pahler J, Olson P et al. Smad4 is dispensable for normal pancreas development yet critical in progression and tumor biology of pancreas cancer. Genes Dev 2006; 20: 3130-3146.

42. Chen WB, Lenschow W, Tiede K, Fischer JW, Kalthoff H, Ungefroren H. Smad4/DPC4dependent regulation of biglycan gene expression by transforming growth factor-beta in pancreatic tumor cells. J Biol Chem 2002; 277: 36118-36128.
43. Staršíchová A, Kubala L, Lincová E, Pernicová Z, Kozubík A, Souček K. Dynamic monitoring of cellular remodeling induced by the transforming growth factor- $\beta 1$. Biol Proced Online 2009; 11: 316-324.

44. Stantic M, Sakil HA, Zirath H, Fang T, Sanz G, Fernandez-Woodbridge A et al. TAp73 suppresses tumor angiogenesis through repression of proangiogenic cytokines and $\mathrm{HIF}-1 \alpha$ activity. Proc Natl Acad Sci USA 2015; 112: 220-225.

45. Amelio I, Antonov AA, Catani MV, Massoud R, Bernassola F, Knight RA et al. TAp73 promotes anabolism. Oncotarget 2014; 5: 12820-12934.

46. Soldevilla B, Millán CS, Bonilla F, Domínguez G. The TP73 complex network: ready for clinical translation in cancer? Genes Chromosomes Cancer 2013; 52: 989-1006.

47. Elston R, Inman GJ. Crosstalk between p53 and TGF-beta signalling. J Signal Transduct 2012; 2012: 294097.

48. Cordenonsi M, Dupont S, Maretto S, Insinga A, Imbriano C, Piccolo S. Links between tumor suppressors: p53 is required for TGF-beta gene responses by cooperating with Smads. Cell 2003; 113: 301-314.

49. Fang $Y$, Yao Q, Chen Z, Xiang J, William FE, Gibbs RA et al. Genetic and molecular alterations in pancreatic cancer: implications for personalized medicine. Med Sci Monit2013; 19: 916-926.

50. Herreros-Villanueva M, Hijona E, Cosme A, Bujanda L. Mouse models of pancreatic cancer. World J Gastroenterol 2012; 18: 1286-1294.

51. Das S, Batra SK. Pancreatic cancer metastasis: are we being pre-EMTed? Curr Pharm Des 2014; 21: 1249-1255.

52. Hotz B, Arndt M, Dullat S, Bhargava S, Buhr HJ, Hotz HG. Epithelial to mesenchymal transition: expression of the regulators snail, slug, and twist in pancreatic cancer. Clin Cancer Res 2007; 13: 4769-4776.

53. Boivin WA, Shackleford M, Vanden Hoek A, Zhao H, Hackett TL, Knight DA et al. Granzyme $B$ cleaves decorin, biglycan and soluble betaglycan, releasing active transforming growth factor- $\beta 1$. PLoS One 2012; 7: e33163.

54. Jacobs EJ, Newton CC, Silverman DT, Nogueira LM, Albanes D, Männistö S et al. Serum transforming growth factor- $\beta 1$ and risk of pancreatic cancer in three prospective cohort studies. Cancer Causes Control 2014; 25: 1083-1091.

55. Biswas S, Guix M, Rinehart C, Dugger TC, Chytil A, Moses HL et al. Inhibition of TGF-beta with neutralizing antibodies prevents radiation-induced acceleration of metastatic cancer progression. J Clin Invest 2007; 117: 1305-1313.

56. Sideras K, Braat H, Kwekkeboom J, van Eijck CH, Peppelenbosch MP, Sleijfer S et al. Role of the immune system in pancreatic cancer progression and immune modulating treatment strategies. Cancer Treat Rev 2014; 40: 513-522.

57. Neuzillet C, de Gramont A, Tijeras-Raballand A, de Mestier L, Cros J, Faivre S et al. Perspectives of TGF- $\beta$ inhibition in pancreatic and hepatocellular carcinomas. Oncotarget 2014; 5: 78-94.

58. Herman JM, Fan KY, Wild AT, Wood LD, Blackford AL, Donehower RC et al. Correlation of Smad4 status with outcomes in patients receiving erlotinib combined with adjuvant chemoradiation and chemotherapy after resection for pancreatic adenocarcinoma. Int $J$ Radiat Oncol Biol Phys 2013; 87: 458-459.

59. Guillaumond F, Leca J, Olivares $O$, Lavaut MN, Vidal N, Berthezène $P$ et al. Strengthened glycolysis under hypoxia supports tumor symbiosis and hexosamine biosynthesis in pancreatic adenocarcinoma. Proc Natl Acad Sci USA 2013; 110: 3919-3924.

60. Schwacke JH, Hill EG, Krug EL, Comte-Walters S, Schey KL. iQuantitator: a tool for protein expression inference using iTRAQ. BMC Bioinformatics 2009; 10: 342.

61. Zhou S, Zawel L, Lengauer C, Kinzler KW, Vogelstein B. Characterization of human FAST-1, a TGF beta and activin signal transducer. Mol Cell 1998; 2: 121-127.

\section{Supplementary Information accompanies this paper on Cell Death and Differentiation website (http://www.nature.com/cdd)}

